\title{
Evaluation of Hypervelocity Carbon Dioxide Blunt Body Experiments in an Expansion Tube Facility
}

\author{
M. Sharma, A B. Swantek† W. Flaherty ; J. M. Austin§, \\ University of Illinois at Urbana-Champaign, IL 61801

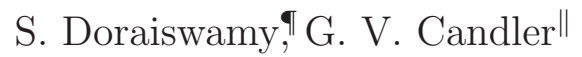 \\ University of Minnesota, Minneapolis, MN 55455
}

\begin{abstract}
This work represents efforts to study high-enthalpy carbon dioxide flows in anticipation of the upcoming Mars Science Laboratory (MSL) and future missions. The current study extends the previous presentation of experimental results by the comparison now with axisymmetric simulations incorporating detailed thermochemical modeling. The work is motivated by observed anomalies between experimental and numerical studies in hypervelocity impulse facilities. In this work, experiments are conducted in the Hypervelocity Expansion Tube (HET) which, by virtue of its flow acceleration process, exhibits minimal freestream dissociation in comparison to reflected shock tunnels. This simplifies the comparison with computational result as freestream dissociation and considerable thermochemical excitation can be neglected. Shock shapes of the Laboratory aeroshell and spherical geometries are compared with numerical simulations. In an effort to address surface chemistry issues arising from high-enthalpy carbon dioxide ground-test based experiments, spherical stagnation point and aeroshell heat transfer distributions are also compared with simulation. The shock stand-off distance has been identified in the past as sensitive to the thermochemical state and as such, is used here as an experimental measureable for comparison with CFD and two different theoretical models. For low-density, small-scale experiments it is seen that models based upon assumptions of large binary scaling values are unable to match the experimental and numerical results. Very good agreement between experiment and CFD is seen for all shock shapes and heat transfer distributions fall within the non-catalytic and super-catalytic solutions.
\end{abstract}

\footnotetext{
${ }^{*}$ Currently Post-Doctoral Research Fellow, Department of Aerospace Engineering and Engineering Mechanics, University of Texas at Austin, Member AIAA

${ }^{\dagger}$ Graduate Student, Department of Aerospace Engineering, Member AIAA

${ }^{\ddagger}$ Graduate Student, Department of Aerospace Engineering, Member AIAA

$\S$ Assistant Professor, Department of Aerospace Engineering,Senior Member AIAA

๑Post-Doctoral Research Fellow, Aerospace Engineering and Mechanics, University of Minnesota, Member AIAA

${ }^{\|}$Professor, Aerospace Engineering and Mechanics, University of Minnesota, AIAA Fellow
} 


\section{Review of High-Enthalpy Carbon Dioxide Work}

In high-enthalpy hypersonic flight, thermochemical relaxation times are typically comparable to flow residence times, leading to nonlinear coupling between chemical reaction, vibrational excitation, and fluid mechanics. In carbon dioxide flows which are relevant to Martian planetary entry, thermochemical effects are particularly significant and may potentially account for some recent anomalous results in blunt body shock layers.

The bow shock flowfield is complex, involving entropy gradients, mixed subsonic and supersonic regions and is three-dimensional. A strong bow shock forms in front of any blunt-nosed capsule, with the shock stand-off distance, $\Delta$, along the stagnation line of the shock layer. This shock stand-off distance is known to be sensitive to the thermochemical state of the region between the shock and the body. ${ }^{1,2}$ It therefore serves as an important experimentally measurable parameter in hypervelocity flowfields.

For sufficiently high freestream velocities, shock layer emission from excited species will increase the heat transfer to the surface above conventional convective heating values via radiative heating. Heat transfer can also be augmented via surface catalysis, whereby dissociated species recombine to form $\mathrm{CO}_{2}$. A non-catalytic surface results in the lowest heating rates as no recombination occurs. The super-catalytic case is the exact opposite in the sense that full recombination at the surface is assumed irregardless of the local equilibrium conditions. It represents the upper bound on the heat transfer prediction as the gas is returned to its lowest chemical state and hence the maximum amount of heat is released. In between the non-catalytic and super-catalytic solutions is finite-rate catalysis where the incident gas-phase species recombine directly with a previously adsorbed atom or molecule. ${ }^{3}$

The collection of high quality, repeatable high enthalpy $\mathrm{CO}_{2}$ data is very important for the validation of numerical models. As computing power increases and physical modeling improves, significant cost-saving can be achieved if computation is able to correct replicate the flow physics. However, current $\mathrm{CO}_{2}$ physical models do carry moderate to significant areas of uncertainty. The two-temperature model described above was developed for air flows and has been applied to $\mathrm{CO}_{2}$ with minimal validation. ${ }^{4}$ There is considerable uncertainty in the current chemical kinetics of a shock heated $\mathrm{CO}_{2}-\mathrm{N}_{2}$ mixture as many of the reactions have not been validated at conditions typical of Martian re-entry. Catalytic properties of dissociated $\mathrm{CO}_{2}$ materials are not as well characterized as those in air. Despite expected MSL turbulence transition, the simple engineering correlation using $\operatorname{Re}_{\theta}$ and $\mathrm{M}_{e}$ is usually employed and a more accurate assesment may be required. Additionally, no validated non-equilibrium $\mathrm{CO}_{2}$ radiative heating model exists.

Current deficiencies in our knowledge of non-equilibrium $\mathrm{CO}_{2}$ have practical design consequences. The MSL currently carries a $50 \%$ uncertainty on its predicted turbulent heating levels, ${ }^{5}$ which results in a considerable TPS (Thermal Protection System) weight penalty. Depending on which catalysis model is used (for which the catalysis effects are not particulary well characterized or modeled), the predicted centerline heating spans heat flux values ranging from 37 to $125 \mathrm{~W} / \mathrm{cm}^{2} .^{3}$

Several researchers have experimentally studied high-enthalpy $\mathrm{CO}_{2}$ flow over blunt bodies. Stewart and Chen measured bow shock stand-off distances over a 140 degree blunt angle cone (an early version of the MSL model) for a $14.3 \mathrm{MJ} / \mathrm{kg}$ pure $\mathrm{CO}_{2}$ run condition in the NASA Ames 42-inch shock tunnel. ${ }^{6}$ Of the three different gas mixtures investigated for the same blunt body, the maximum discrepancy between computation and experiment in the shock stand-off distance was observed for the pure $\mathrm{CO}_{2}$ condition. 
In the T5 facility, Wen and Hornung compared non-equilibrium theoretical sphere shock standoff distance predictions with extensive experimental and numerical results and found acceptable agreement. ${ }^{1}$ In the reflected shock tunnel HEG, $\mathrm{CO}_{2}$ flow over a 70 -degree blunt cone was studied using simulations and experiments by Netterfield et al. ${ }^{7}$

Hollis and Perkins compared various sphere-cone model forebody and aftbody heat transfer values with computational simulations in the HYPULSE expansion tube ${ }^{8,9}$ and the 31-inch Mach 10 Langley wind tunnel. ${ }^{8}$ Overall, very good agreement between CFD and experiment was achieved.

\section{A. CUBRC Results}

The hypersonic facilities at Calspan-University of Buffalo Research Center (CUBRC) have been central to the investigation of planetary entry flight conditions for many programs, including the up-coming MSL mission. Recent studies revealed that the experimentally observed shock shape and stand-off distance differed significantly from numerical simulations over a 24" diameter MSL model for high-enthalpy test conditions at 5 and $10 \mathrm{MJ} / \mathrm{kg}$ in the LENS I reflected shock tunnel facility. ${ }^{10}$ The computed shock stand-off distance for the $5 \mathrm{MJ} / \mathrm{kg}$ test condition was a factor of 2.25 times smaller than the experimental value as shown in Figure 1, for which this discrepancy is clearly visible. However, at a $2 \mathrm{MJ} / \mathrm{kg}$ test condition in the same facility, no such differences were observed. To examine this discrepancy further, the same model was tested in the LENS X expansion tube facility at $5 \mathrm{MJ} / \mathrm{kg} .{ }^{10}$ Excellent agreement was obtained between simulations and experiments in the LENS X facility.

It was proposed that a possible cause for the observed reflected shock tunnel discrepancy was

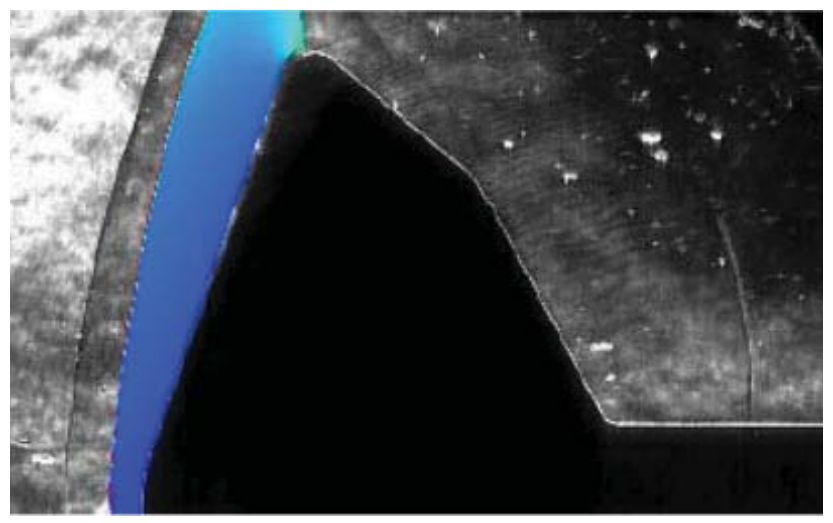

Figure 1: Comparison between experimental and numerical shock shape on a 24 inch diameter MSL model in the LENS I facility for a nominal $5.63 \mathrm{MJ} / \mathrm{kg}$ run condition. Image re-produced with permission from Matt MacLean of CUBRC.

due to uncertainty in the thermochemical state of the freestream after the chemically dissociated test gas is strongly expanded in the nozzle. A follow-up numerical study found that shock shape and stand-off distance matched experimental observation when $42 \%$ of the total energy was artificially frozen in vibration. ${ }^{11}$ As discussed by the authors, such a result is clearly aphysical and especially so when one considers that the original calculation had $3.6 \%$ of the total energy frozen in vibration. Additionally, frozen vibrational energy was seen to have a greater impact upon the shock stand-off distance than frozen chemical energy. As mentioned above, for a very similar run 
condition, such a discrepancy was not observed in an expansion tunnel facility. This suggests that complex $\mathrm{CO}_{2}$ system vibrational relaxation processes, such as those occuring in the reflected shock tunnel nozzle, may not be completely understood.

The previously discussed CUBRC experiments formed a component of a very comprehensive investigation of high-enthalpy $\mathrm{CO}_{2}$ sphere-cone blunt body flow fields, incorporating several facilities and extensive numerical modeling. In the Caltech T5 facility, a series of shots for a $70^{\circ}$ blunt cone were conducted, and surface heat flux measurements obtained. At angle of attack, it was observed that super-catalytic simulations agreed best with laminar windside data whereas the turbulent leeside was most accurately predicted by the non-catalytic cases. ${ }^{3}$ Similar results were also observed for LENS experiments when the model was initially coated in $\mathrm{SiO}_{2}$ to promote a non-catalytic response. ${ }^{4}$ In LENS I, at zero angle of attack, for all locations away from the nose, measurements were best matched with the aphysical super-catalytic boundary condition. ${ }^{12}$ The authors commented that the uncertainty in the freestream (due to dissociation) is expected to explain some, but not all, of the discrepancies between heat transfer prediction and measurement. Laboratory experiments which investigated surface reactions involving dissociated $\mathrm{CO}_{2}$ found no evidence for the depletion of $\mathrm{CO}$ by surface reaction at either room temperature of $250^{\circ} \mathrm{C}$. ${ }^{13}$ Such a result is inconsistent with the robust $\mathrm{CO}$ oxidation reactions required to enforce the super-catalytic boundary condition. This provides further motivation to collect additional data and compare heat transfer measurements with simulations incorporating catalytic boundary conditions.

\section{Scope of Current Work}

At the cost of reduced test time and potential loss in core flow, expansion tubes are capable of producing high-enthalpy conditions while the degree of freestream dissociation is significantly reduced in comparison to reflected shock tunnels. In a reflected shock tunnel, chemical and vibrational freezing can occur downstream from the nozzle throat, which as discussed above can alter the test conditions in a complex manner. In the present work, the HET is used to provide additional high-enthalpy $\mathrm{CO}_{2}$ data and compare with numerical results.

In this study, we first obtain a suitable test condition with first-order matching of the highenthalpy CUBRC test case. Next, spherical models of different diameters (7.9 to $63.5 \mathrm{~mm}$ ) are examined as a canonical flow field and measured shock stand-off distances compared with theoretical prediction. Sphere shock layer shapes are compared with axisymmetric simulations using the US3D code. ${ }^{14}$ These comparisons are useful for additional verification of facility operation, as well as for validation of future computational simulations and thermochemical models. For the same test condition, shock shapes over a MSL model geometry at three flight angles of attack $(0,11$ and 16 degrees) are obtained and also compared with simulations. At each angle of attack, surface heat flux measurements were made using co-axial thermocouples. The heat transfer distributions are compared with calculations assuming non-catalytic and super-catalytic boundary conditions.

\section{Experimental Setup}

The HET is a $9.14 \mathrm{~m}$ long facility consisting of three sections (driver, driven, and accelerator) all with $150 \mathrm{~mm}$ inner bore diameter, initially separated by primary and secondary diaphragms, Figure 2. The initial gas pressure and composition can be varied to achieve nominal Mach numbers of between 3.0 to 7.5 and stagnation enthalpies of between 4.5 to $8.0 \mathrm{MJ} / \mathrm{kg}$. The facility is initially 
evacuated, then each section filled to the desired initial pressure. The primary diaphragm burst pressure (driver pressure) is measured using a Setra 206 pressure gauge. Driven and accelerator initial fill pressures are monitored using MKS Piezo+ A900-02 transducers. Vacuum pressures (below 2000 mTorr) in the accelerator section are measured using a MKS Baratron 626A transducer with 2 Torr fullscale, rated to $0.25 \%$ of the reading. A full description of the facility, measurement capabilities and facility operation can be found in Dufrene et al. ${ }^{15}$ Facility operation has been previously characterized experimentally and numerically. ${ }^{15-17}$

Shock shapes are visualized using a schlieren system consisting of a Xenon nanopulser (10 ns

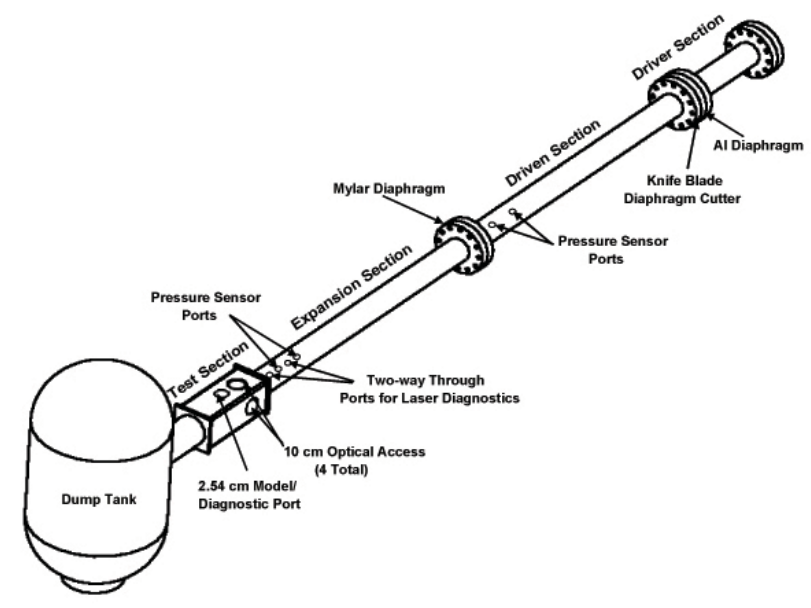

Figure 2: Schematic of the HET facility.

duration) white light source and pco.1660 (Cooke Coorporation) CCD camera. The system is triggered via the transmitted shock arrival at a $1 \mathrm{MHz}$ response pitot pressure transducer (PCB 113A26) sting-mounted in the test section $63.5 \mathrm{~mm}$ below the model centerline.

The spheres and MSL are mounted within the test section such that their axial centerlines approximately correspond with the tube centerline. The 11 and 16 degree angle of attack positions were achieved by mounting the MSL model on triangular spacer blocks, whose hypotenuse was angled at the desired angle of attack from the vertical. The spheres and MSL were made from Al 2024 and A2 tool steel respectively. With a major diameter of $50.8 \mathrm{~mm}$, the MSL model used in this study is approximately $1 / 100$ th the size of the actual vehicle. The scaled down dimensions of the MSL were designed according to those specified in Hollis et al. ${ }^{18}$ As with the actual vehicle, the model has a 70 degree sphere cone forebody, however the current model only has single conic (40 degree) aftbody whilst the actual vehicle is biconic. The MSL model, instrumented with thermocouples, is shown in Figure 3.

The thermocouples used in these experiments are based on the design of Sanderson. ${ }^{19}$ They are coaxial, $2.4 \mathrm{~mm}$ in diameter, type $\mathrm{E}$ (Constantan-Chromel), and mount flush with the surface of a model. The two coaxial elements are designed such that an extremely thin junction (on the order of $1 \mu \mathrm{m}$ ) is formed at the surface. This type of thermocouple gauge is used extensively in the T5 reflected shock tunnel, ${ }^{19-21}$ where the high enthalpy test conditions result in adequate signal levels and the robust design of the gauges make them highly resistant to damage caused by particulates in the test gas as well as the large heat fluxes. ${ }^{19}$ The output signal is processed by a differential 


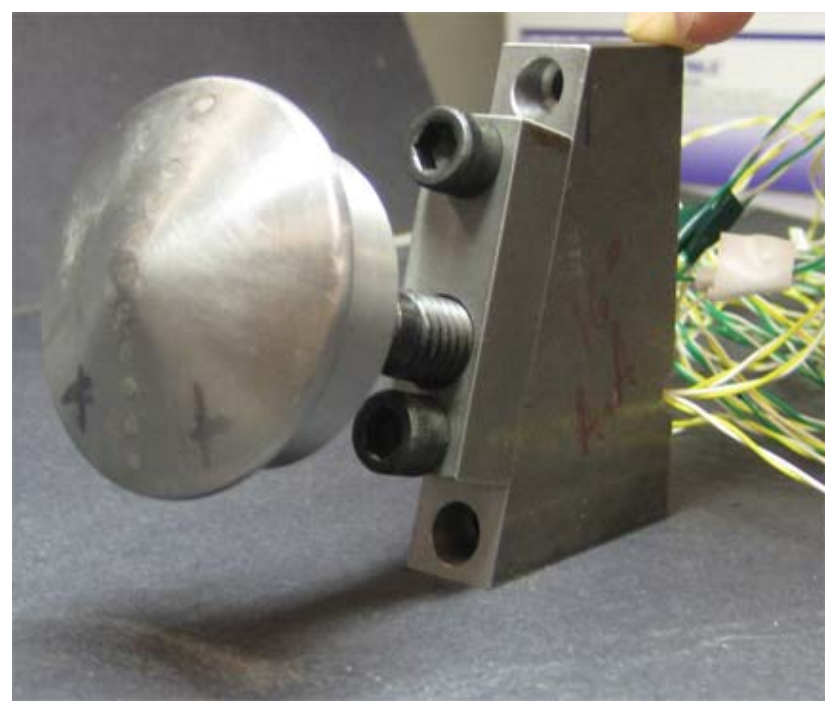

Figure 3: MSL model, machined from A2 tool steel with a major diameter of 2 inches.

amplifier circuit mounted exterior to the test section. This also serves to eliminate the effects of any extraneous electromotive forces generated by the thermocouple. The circuit gain is 1000 to maximize signal amplitude. Individual calibration of thermocouples is not necessary, since the temperature response of all common thermocouple types is well known. The NIST thermocouple reference tables were used to convert from voltage to temperature. ${ }^{22}$ For more information regarding the development, testing and performance verification of the thermocouples, see Flaherty and Austin. ${ }^{23}$

\section{Numerical Modeling}

The simulations were conducted using the code US3D developed at the University of Minnesota. ${ }^{14}$ US3D is a hybrid, implicit unstructured finite volume code that solves the compressible Navier-Stokes equations. The inviscid fluxes are calculated using a low dissipation version of StegerWarming flux vextor splitting. Second order accuracy in space is achieved using an upwind biased MUSCL approach. Implicit time integration is performed using a parallel line relaxation procedure. The grid was adapted to align with the bow shock wave to improve the accuracy of the solutions.

The state-specific vibrational model of Doraiswamy et al. for the $\mathrm{CO}_{2}-\mathrm{CO}-\mathrm{O}_{2}-\mathrm{O}$ system is employed $^{24}$ for thermochemical modeling. In this model, the symmetric stretch and bending modes of $\mathrm{CO}_{2}$ are grouped together due to the Fermi resonance between the modes, and these modes are assumed to be in equilibrium with the translational modes. The antisymmetric mode is considered separately and relaxes toward equilibrium with finite-rate vibration-translation and vibrationvibration processes. The first few vibrational states are considered for each species up to a limit of $8000 \mathrm{~cm}^{-1}$ above the ground state. Each vibrational level is treated as a separate species, with a total of 15 state-specific levels considered (4 levels for $\mathrm{CO}_{2}, 5$ for $\mathrm{CO}, 6$ for $\mathrm{O}_{2}$ ). The vibrational relaxation model has been shown to reproduce experimental measurements, and a complete description is given in Doraiswamy et al. ${ }^{24}$ 
The three chemical reactions that describe the $\mathrm{CO}_{2}-\mathrm{CO}-\mathrm{O}_{2}-\mathrm{O}$ system are taken to be

$$
\begin{gathered}
\mathrm{CO}_{2}+\mathrm{M} \leftrightharpoons \mathrm{CO}+\mathrm{O}+\mathrm{M} \\
\mathrm{O}_{2}+\mathrm{M} \leftrightharpoons \mathrm{O}+\mathrm{O}+\mathrm{M} \\
\mathrm{CO}_{2}+\mathrm{O} \leftrightharpoons \mathrm{CO}+\mathrm{O}_{2}
\end{gathered}
$$

Standard rate constants for these reactions are used. ${ }^{24}$

\section{Results and Discussion}

\section{A. Criteria for Selection of Experimental Test Conditions}

Carbon dioxide test gas conditions are selected to match the relevant experimental parameters in CUBRC facilities as closely as possible. Since in general all test parameters cannot be matched from facility to facility, identification of the dominant flow properties for a particular measurement is important in comparative ground testing as well as in flight simulation. One aspect of the present study is to evaluate what parameters should be matched for adequate comparative measurements of shock shape and heat transfer in different expansion tube facilities. Simulations of blunt bodies in nitrogen flows by Macrossan showed that free stream dissociation had little effect on the bow shock at different angles of attack ${ }^{25}$ indicating that in nitrogen, the degree of dissociation in shock tunnel versus flight tests was less important to match than the Mach number.

The discrepancy between the CUBRC LENS X and LENS I results was observed for test conditions with $5.63 \mathrm{MJ} / \mathrm{kg}$ stagnation enthalpy in $\mathrm{CO}_{2} \cdot{ }^{11}$ For the same stagnation enthalpy, we select the test gas velocity as the first-order matching parameter due to the large kinetic energy contribution to the total enthalpy. Matching the CUBRC condition in the HET requires a test gas velocity of $3036 \mathrm{~m} / \mathrm{s}$. Higher order matching could be achieved by using the frozen Mach number as a selection parameter, however the LENS X run condition frozen Mach number is 11.81, which is outside the operating regime of the HET.

In an expansion tube, for a fixed test gas composition and driver pressure, test gas properties can be changed by either altering the initial driven pressure, $\mathrm{p}_{1}$, or the initial acceleration section conditions $\left(\gamma_{5}, \mathrm{p}_{5}\right)$. Table 1 presents properties for four different run conditions. Here state 7 denotes the test condition ${ }^{15}$ and $M$ is the Mach number, $h_{s t a g, 7}$ is the stagnation enthalpy, $T$ is the temperature and $\rho$ is the density. In each case, the test gas velocity, $u_{7}$, is within $1.3 \%$ of the CUBRC test gas velocity. Transmitted shock velocity, $u_{t}$, is typically accurate to within $\pm 43 \mathrm{~m} / \mathrm{s}$ in the HET and it is expected that similar error bars will exist for test gas velocity measurements. ${ }^{26}$ In the first column, the test conditions were generated by varying the acceleration section gas; here argon, helium, air and carbon dioxide are used. The test conditions are described in terms of the driven-accelerator gas combination. The driven section pressure, $\mathrm{p}_{1}$, is kept constant in each case and $\mathrm{p}_{5}$ chosen so as to match the test gas velocity requirement. In each case the driver gas is helium and the driver pressure is kept constant at roughly 2.5 MPa. Additional criteria are then considered to achieve a well-characterized and uniform freestream. The expanded driver to driven gas sound speed ratio should be maintained below certain threshold values to reduce freestream disturbances. ${ }^{15,27}$ The test time begins with the arrival of the driven to accelerator (secondary) gas interface and broadening of this interface should be minimized. Significant distortion of the contact surface and test time reduction was reported when carbon dioxide was used in both driven and 


\begin{tabular}{|c|c|c|c|c|c|c|c|c|c|}
\hline Interface & $\begin{array}{c}p_{1} \\
(\mathrm{kPa})\end{array}$ & $\begin{array}{c}p_{5} \\
(\mathrm{~m} \text { Torr })\end{array}$ & $\begin{array}{c}u_{7} \\
(\mathrm{~m} / \mathrm{s})\end{array}$ & $\begin{array}{c}h_{\text {stag }, 7} \\
(\mathrm{MJ} / \mathrm{kg})\end{array}$ & $M_{7}$ & $\begin{array}{c}T_{7} \\
(\mathrm{~K})\end{array}$ & $\begin{array}{c}\rho_{7} \\
\left(\mathrm{~kg} / \mathrm{m}^{3}\right)\end{array}$ & $\begin{array}{c}u_{t} \\
(\mathrm{~m} / \mathrm{s})\end{array}$ & $\begin{array}{c}\text { Test Time } \\
(\mu \mathrm{s})\end{array}$ \\
\hline $\mathrm{CO}_{2}$-CO 2 (RC2) & 1.2 & 150 & 2998 & 5.51 & 5.52 & 1212 & 0.016 & 3454 & 293 \\
\hline $\mathrm{CO}_{2}$-Air (RC5) & 1.2 & 180 & 3059 & 5.66 & 5.72 & 1172 & 0.014 & 3698 & 274 \\
\hline $\mathrm{CO}_{2}$-Hel (RC8) & 1.2 & 1050 & 3066 & 5.68 & 5.75 & 1168 & 0.014 & 4328 & 272 \\
\hline $\mathrm{CO}_{2}$-Arg (RC11) & 1.2 & 135 & 3014 & 5.55 & 5.57 & 1201 & 0.016 & 4045 & 288 \\
\hline
\end{tabular}

Table 1: Properties for candidate HET test conditions. Initial fill conditions differ by the choice of acceleration gas.

accelerator sections in the JX-1 facilty. ${ }^{28}$ To minimize broadening, air is selected as the accelerator gas.

Estimates of the shock stand-off distance were made for candidate test conditions using the theory of Wen and Hornung. ${ }^{1}$ For non-equilibrium flows, Lick applied inverse methods to calculate shock shape in front of a sphere ${ }^{29}$ and his work was extended by Hall et al. ${ }^{30}$ Using the ideal dissociating gas model (diatomic gas), Hornung investigated non-equilibrium flow over spheres and cylinders. ${ }^{31}$ Extending Hornung's original work to more complex gases, Wen and Hornung carried out a joint theoretical and experimental study of non-equilibrium dissociating flow over spheres and developed a model for the stand-off distance in terms of a modified dimensionless reaction rate parameter. $^{1}$ Inger et al. presented a hypersonic shock stand-off theory, incorporating nonequilibrium gas mixtures with freestream dissociation, based upon a compressibility co-ordinate transformation. ${ }^{32}$ A theoretical model for the non-equilibrium shock stand-off distance was also introduced by Belouggadia et al, ${ }^{33}$ following an analytical solution proposed by Olivier. ${ }^{34}$ The Olivier solution was confined to frozen and equilibrium flows, while the numerical model of Belouggadia et al. implemented calculated density profiles. At the post-shock to equilibrium density ratios in the present experiments, we find there is very little difference between density profiles calculated by the Wen and Hornung and Belouggadia et al. methods. As a result, the theory of Wen and Hornung is used in this study.

The shock stand-off distance is known to be inversely proportional to the average density on the stagnation streamline. ${ }^{1,31}$ In their inviscid analysis, Wen and Hornung assumed a simplified density profile along the shock stagnation-line. They defined a non-dimensional shock stand-off distance, $\widetilde{\Delta}$, as:

$$
\tilde{\Delta}=\frac{\rho_{s}}{\rho_{\infty}} \frac{\Delta}{d}
$$

where $\rho_{\infty}$ is the freestream density, $\Delta$ is the shock stand-off distance and $d$ is the sphere diameter. The theory admits the calculation of $\widetilde{\Delta}$ in terms of a dimensionless reaction rate parameter, $\widetilde{\Omega}$. $\widetilde{\Omega}$ has the physical significance of being the ratio of the energy absorption rate by chemistry to the free-stream kinetic energy input rate. Physically, a zero $\tilde{\Omega}$ corresponds to frozen conditions (no dissociation) and an infinite value corresponds to very fast reactions and equilibrium. In between these two limits, two conditions exist: a fully non-equilibrium shock layer and a shock layer with both non-equilibrium and equilibrium portions. Wen and Hornung derived the following relationships for a fully non-equilibrium shock layer and a partial non-equilibrium, partial equilibrium shock layer respectively

$$
\tilde{\Delta}=\frac{1}{\tilde{\Omega}}[-1+\sqrt{1+2 L \tilde{\Omega}}]
$$




$$
\tilde{\Delta}=\frac{\rho_{s}}{\rho_{e}}\left[L+\frac{1}{2 \tilde{\Omega}}\left(\frac{\rho_{e}}{\rho_{s}}-1\right)^{2}\right]
$$

where $\rho_{e}$ and $\rho_{s}$ are the equilibrium and post-shock density respectively and $\mathrm{L}$ is taken to be equal to 0.41 for spheres. ${ }^{1}$ The Mach numbers for the four test conditions are very similar and hence the variation in shock stand-off distance will be very small. Therefore, no effective experimental benefit in terms of the shock stand-off distance is achieved by selecting one condition over another. For a $50.8 \mathrm{~mm}$ sphere with a frozen shock layer $(\tilde{\Omega}=0)$, the shock stand-off distance across the four candidate run conditions varies by only $0.3 \mathrm{~mm}$, which offers no experimental advantage.

Based on the above considerations, a helium driver and air accelerator section test condition was selected and denoted as RC5. The test gas properties are computed with inviscid, perfect-gas, one-dimensional gas dynamic calculations and are presented in Table 2 together with corresponding experimental measurements. Here $u_{s}$ is the shock speed in the driven section and $p_{7, p i t o t}$ is the test gas pitot pressure. All the experimental values are averaged values across a number of realizations for repeatability. The pitot pressure measurements were obtained $6.35 \mathrm{~mm}$ below the tube centerline. Static pressure values were obtained at two stations, $30.48 \mathrm{~cm}$ and $55.88 \mathrm{~cm}$, upstream from the tube exit.

There is a discrepancy between the experimental and theoretical pitot pressure value. The

\begin{tabular}{|c|c|c|c|c|c|c|c|c|c|}
\hline & $M_{7}$ & $\begin{array}{c}h_{o, 7} \\
(\mathrm{MJ} / \mathrm{kg})\end{array}$ & $\begin{array}{c}\text { Test Time } \\
(\mu \mathrm{s})\end{array}$ & $\begin{array}{c}P_{7, \text { pitot }} \\
(\mathrm{kPa})\end{array}$ & $\begin{array}{c}P_{7} \\
(\mathrm{kPa})\end{array}$ & $\begin{array}{c}u_{t} \\
(\mathrm{~m} / \mathrm{s})\end{array}$ & $\begin{array}{c}u_{7} \\
(\mathrm{~m} / \mathrm{s})\end{array}$ & $\begin{array}{c}u_{s} \\
(\mathrm{~m} / \mathrm{s})\end{array}$ & $\begin{array}{c}\phi \\
(\mathrm{mm})\end{array}$ \\
\hline Exp. & - & - & 150 & $82.0 \pm 4.0$ & $2.7 \pm 0.3$ & $3644 \pm 41$ & - & $1832 \pm 38$ & 114.3 \\
\hline Theo. & 5.7 & 5.67 & 274 & 128.3 & 3.2 & 3710 & 3059 & 1853 & 105.4 \\
\hline
\end{tabular}

Table 2: Selected test condition (RC5) parameters. Theoretical calculations assuming onedimensional, perfect gas dynamics. Comparison with experimental measurements.

theoretical test gas pitot pressure is calculated assuming an inviscid, perfect gas. The equilibrium pitot pressure is calculated to be $119 \mathrm{kPa}$, clearly not a sufficient reduction to match the experimental value. The discrepancy in pitot pressure is currently under investigation. The transmitted shock speed was also measured in the test section using the shock time-of-arrival at staggered pitot probes. This approach has been used in the past to characterize a test condition and in that instance, it was found that the measurement agreed with computational results. ${ }^{35}$ Experimental pitot surveys of the core flow at this test condition were carried out to determine that the maximum model diameter that can be chosen is about $65 \mathrm{~mm}$.

\section{B. Sphere shock shapes}

We initially examine spherical models in benchmark tests for which results can be compared with theoretical predictions and numerical simulations. This flowfield provides additional verification of facility operation via numerical simulations and thermochemical calculations with a relatively simple geometry. Shock stand-off distances over a sphere have been previously investigated in nonequilibrium air and nitrogen flows. ${ }^{31,36}$ As discussed in Section I, Wen and Hornung measured shock stand-off distances over spheres in a high-enthalpy carbon dioxide flow field. ${ }^{1}$ Outstanding issues in a carbon dioxide flowfield still remain, including the role of thermochemical energy storage and transfer and the possibility of facility-specific data. Therefore, the measurement of shock 
stand-off distances for similar enthalpy conditions in another hypervelocity facility provide data to complement existing results.

Selected schlieren images for spheres of diameters from 25.4 to $63.5 \mathrm{~mm}$ are shown in Figure 4 a)d) and compared with numerical simulations. Numerical simulations were carried out at the free stream conditions predicted by ideal gas theory, Table 2. The measured and predicted shock standoff distances for each sphere diameter are in very good agreement and within at maximum $10 \%$ of each other, Table 3. The experimental uncertainty on the stand-off distance measurement is estimated to be 1 pixel, or approximately $0.05 \mathrm{~mm}$.

Normalized vibrational temperature contours are shown in Fig 5 a)-d). For all the spherical geometries, the simulated temperature contours predict that the majority of the stagnation line shock layer is in thermal equilibrium and only a small non-equilibrium region exists near the bow shock.

The $\tilde{\Delta}-\tilde{\Omega}$ curve of Wen and Hornung for RC5 is compared against the experimental results,

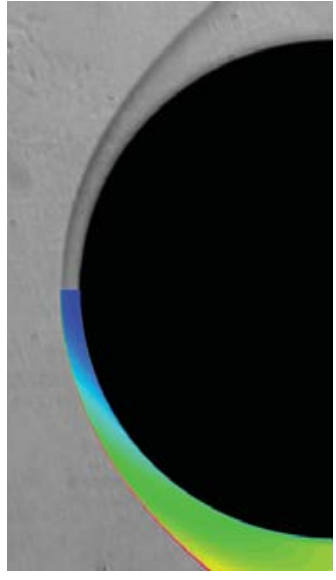

a)

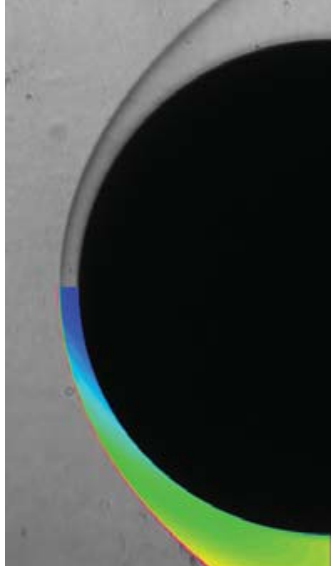

b)

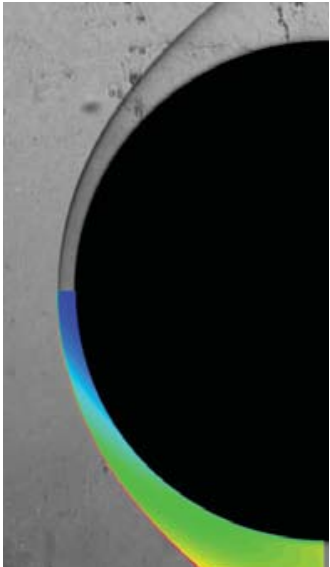

c)

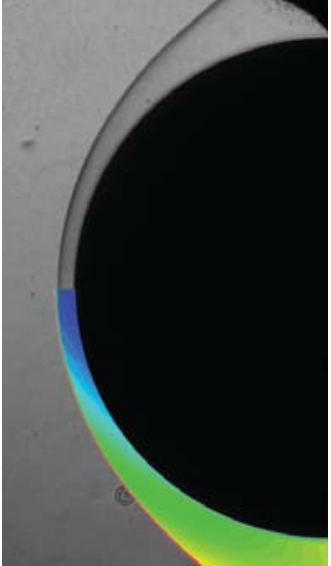

d)

Figure 4: Comparisons of experimental schlieren images and simulations of bow shock shapes over spheres of diameter a) $25.4 \mathrm{~mm}$, b) $37.5 \mathrm{~mm}$, c) $50.8 \mathrm{~mm}$, and d) $63.5 \mathrm{~mm}$.

Figure 6. Here the y-axis is slightly re-cast as another non-dimensional shock stand-off distance, $\frac{\Delta}{d}$. For each sphere, the the reaction rate parameter is calculated according to

$$
\tilde{\Omega}=\frac{d}{\rho_{s} u_{\infty}}\left(\frac{1}{h_{\rho}} \sum_{i=2}^{n} h_{c_{i}} \frac{d c_{i}}{d t}\right)_{s}
$$

here $d$ is the sphere diameter, $u_{\infty}$ is the freesteam velocity, and $c$ is the mass fraction. Subscripts $i$ and $s$ refer to individual species and post-shock values respectively. $h_{\rho}$ and $h_{c}$ are the partial derivatives of the static enthalpy with respect to the density and species mass fractions respectively. The post-shock mass fraction rates are supplied from the numerical calculations. The post-shock conditions directly behind the shock are taken to be the values at which the translational temperature is a maximum.

The predicted values of $\Delta$ for the four spheres from the theory of Wen and Hornung, based 


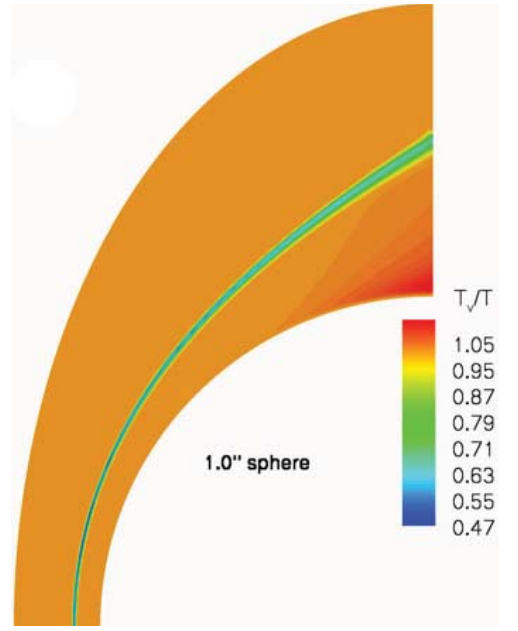

a)

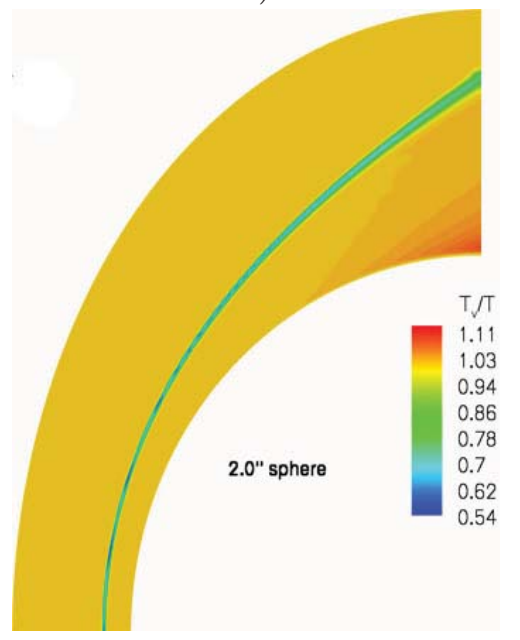

c)

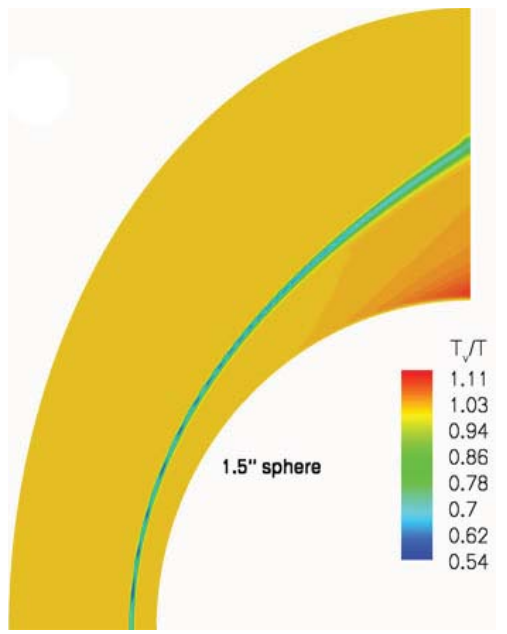

b)

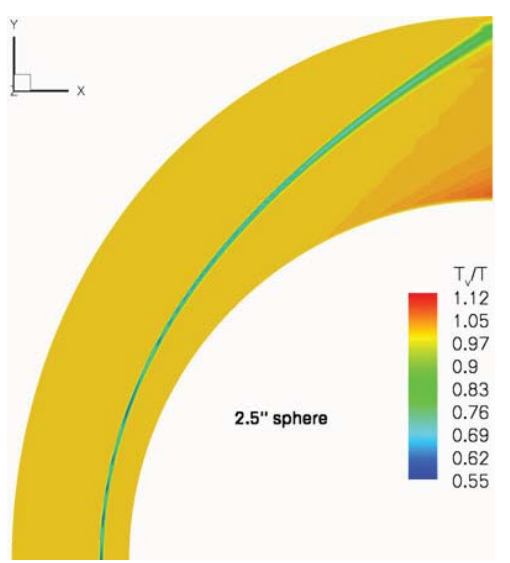

d)

Figure 5: Vibrational temperature contours from US3D simulations for sphere diameters of a) $25.4 \mathrm{~mm}$, b) $37.5 \mathrm{~mm}$, c) $50.8 \mathrm{~mm}$, and d) $63.5 \mathrm{~mm}$. 


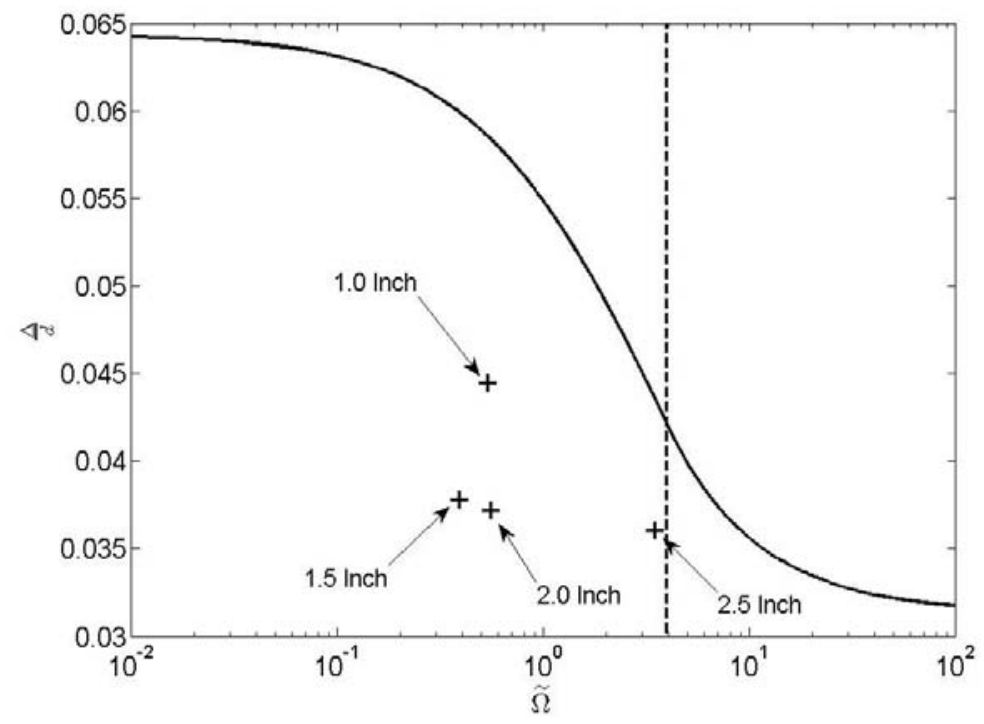

Figure 6: Comparison of normalized experimental stand-off distance (black crosses) with theoretical prediction (solid black line). The point where $\rho_{b}=\rho_{e}$, separating a fully non-equilibrium shock layer from a partial equilibrium/partial non-equilibrium region, is indicated by the dashed vertical line.

upon the calculated $\tilde{\Omega}$ values, are presented in Table 3 . It is clear from both the table and figure that the theoretical prediction does not represent the experimental result. In the table, percentage difference between theory and experiment is included in parentheses. The differences are quite large, but more concerning is that the values do not even match the characteristic shape of the $\tilde{\Delta}-\tilde{\Omega}$ curve. For their theory to be applicable, Wen and Hornung require that the binary scaling, $\rho d$, be sufficiently large. Wen establishes a "rule of thumb" for binary scaling, however this is valid only for a diatomic gas. ${ }^{37}$ In their work, the sphere diameters ranged from 2 to 6 inches and the freestream densities were considerably higher, resulting in $\rho d$ values that are an order of magnitude larger than the RC5 value. For example, for a comparable stagnation enthalpy and Mach number run condition, the maximum T5 $\rho d$ value is $6.87 \times 10^{-3}$ while the maximum HET value is $9.14 \times 10^{-4}$. The results from the T5 facility saw good to very good agreement between the binary-scaling based theory and experimental measurement for stagnation enthalpies ranging from 4.11 to $10.76 \mathrm{MJ} / \mathrm{Kg}$ in nitrogen and $\mathrm{CO}_{2} \cdot{ }^{1,37}$ It therefore appears that the binary scaling values of this study are too small for the experimental conditions to be applicable to Wen and Hornung's theory.

Shock stand-off distances based upon the theory of Inger et al. ${ }^{32}$ were also calculated. The theory implements a compressibility coordinate transformation. It is an inviscid approximation. In their paper, Inger et al. obtained good agreement with the experimental data of Wen and Hornung. ${ }^{1}$ The calculated results are also shown in Table 3. Percentage difference between experiment and theory are shown in parentheses. The coordinate transformation approach has captured the trend observed in the experimental data of an increasing shock stand-off distance with increasing sphere diameter. The theory over-predicts both the experimental measurement and numerical result, with an experimental over-prediction of upto 29\%. Based upon these results, it appears 
that the compressibility coordinate transformation approach is capable of providing a reasonable approximation of shock stand-off distances in non-equilibrium gas flows for low-density, small-scale conditions that otherwise appear not to be applicable for the theory of Wen and Hornung.

Stagnation line density profiles for the four spheres were calculated, Figure 7, and plotted

\begin{tabular}{|c|c|c|c|c|}
\hline Sphere diameter $(\mathrm{mm})$ & $\Delta_{\text {exp }}(\mathrm{mm})$ & $\begin{array}{c}\Delta_{\text {num }}(\mathrm{mm}) \\
\text { US3D }\end{array}$ & $\begin{array}{c}\Delta_{\text {theory }}(\mathrm{mm}) \\
\text { Wen and Hornung }\end{array}$ & $\begin{array}{c}\Delta_{\text {theory }}(\mathrm{mm}) \\
\text { Inger et al. }^{32}\end{array}$ \\
\hline 63.5 & 2.29 & $2.45(7.0)$ & $2.76(20.5)$ & $2.77(21.0)$ \\
\hline 50.8 & 1.89 & $1.98(4.8)$ & $2.97(57.1)$ & $2.43(28.6)$ \\
\hline 38.1 & 1.44 & $1.53(6.3)$ & $2.28(58.3)$ & $1.65(14.6)$ \\
\hline 25.4 & 1.13 & $1.06(-6.2)$ & $1.49(31.9)$ & $1.16(2.7)$ \\
\hline
\end{tabular}

Table 3: Comparison between the experimental shock stand-off distance, the numerical result from US3D and the two theoretical solutions.

against $\frac{y}{\Delta}$, where $\mathrm{y}$ is the distance from the shock. The equilibrium limit, calculated from a $\mathrm{CEA}^{38}$ calculation, is also included. Viscous calculations were performed which are capable of resolving the boundary layer as evidenced by the steep rise in density close to the body. Profiles of $\frac{T_{v}}{T}$, the ratio of vibration-to-translation temperatures, are also presented in Figure 8. Here we see that for all sizes, the major portion of the shock layer is in thermodynamic equilibrium. For all spheres, equilibrium is reached shortly downstream of the shock by $\frac{y}{\Delta}=0.09$. We see that increasing the sphere diameter increases the equilibrium extent within the shock layer. Figure 9 is the shock layer temperature profile for the 1.5 inch sphere. Mass fraction profiles for $\mathrm{CO}, \mathrm{O}$ and $\mathrm{O}_{2}$ and also for $\mathrm{CO}_{2}$ are shown in Figures 10 and 11 respectively for the 1.5 inch sphere. From these figures we can see that thermodynamic equilibrium exists (Figure 8), but not chemical equilibrium as the species concentrations are changing. The chemical non-equilibrium is what accounts for the rising density profile above the equilibrium value as dissociation is a contributing factor to the change in density. This is also reflected in the dimensional temperature profile, Figure 9, where the temperature decreases sharply within the non-equilibrium region and continues to decay throughout the shock layer. This occurs as the dissociation of $\mathrm{CO}_{2}$ increases the chemical energy of the system, which comes at the expense of thermal energy and the subsequent decrease in temperature takes place. From Figure 10, the minor species concentrations increase throughout the shock layer as $\mathrm{CO}_{2}$ dissociates. The depletion of $\mathrm{CO}$ and $\mathrm{O}$ and the increase in $\mathrm{CO}_{2}$ close to the body is indicative of $\mathrm{CO}_{2}$ recombination within the boundary layer. Recombination within the boundary layer suggests an equilibrium boundary layer ${ }^{39}$ and will increase the thermal energy of the flow as chemical energy is released. However, the driving force for the temperature profile within the boundary layer will be the boundary condition of a cold wall.

\section{MSL Shock Shapes at Angle of Attack}

Experimental images and numerical simulations of the bow shock shape over the MSL geometry at three angles of attack are shown in Figure 12. Images show increasing shock stand-off distance with increasing angle of attack. In the non-zero angle of attack images, in particular for the 16 degree case, the shock appears to be spherically shaped on the windward side and more conically shaped over the leeward side. Similar results were also observed by Stewart and Chen. ${ }^{6}$ For the 16 degree 


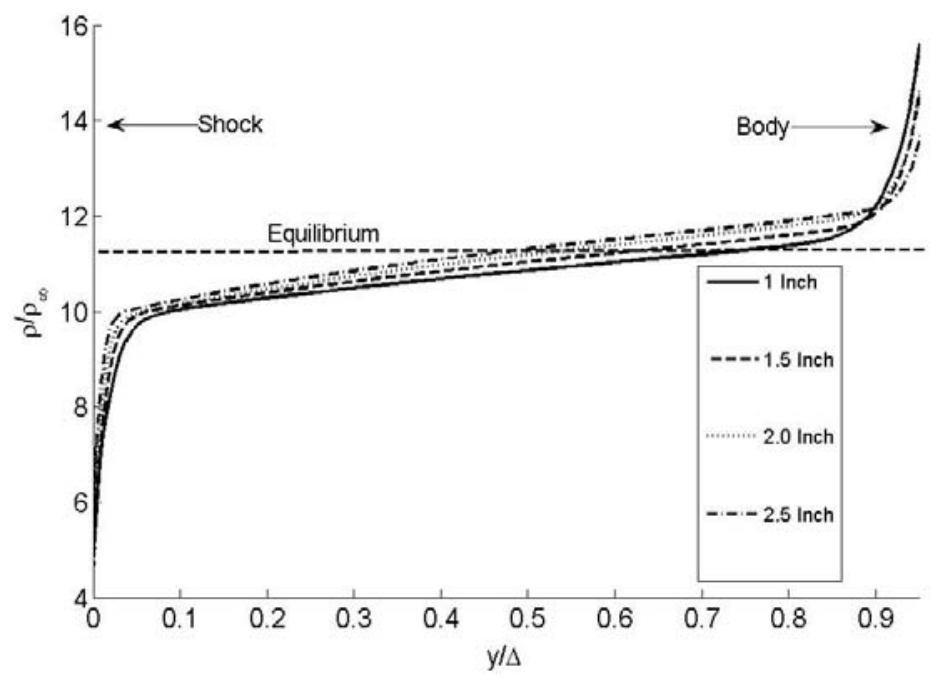

Figure 7: Stagnation line density profile from US3D numerical computations for the 4 different sphere diameters considered in this study: 1, 1.5, 2 and 2.5 inches. Profiles are calculated for freestream conditions predicted by inviscid, perfect-gas HET operation.

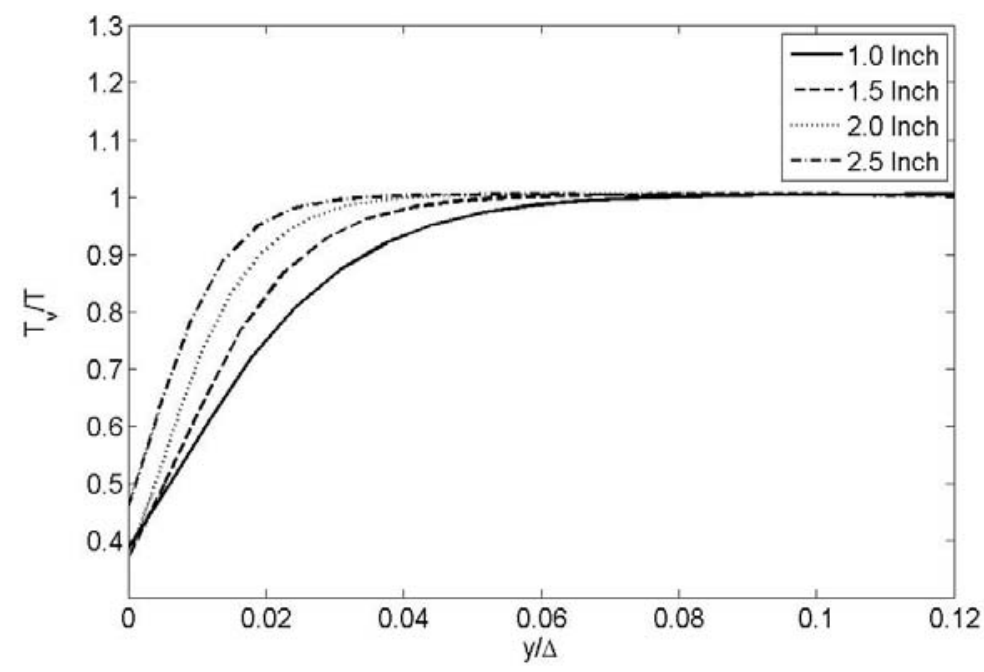

Figure 8: Stagnation line temperature profiles from US3D numerical computations for the 4 different sphere diameters considered in this study: 1,1.5,2 and 2.5 inches. Normalized temperature is presented as the ratio of vibrational temperature to translational temperature. Note that only a small section of the shock layer is plotted as thermal equilibrium is reached very quickly. 


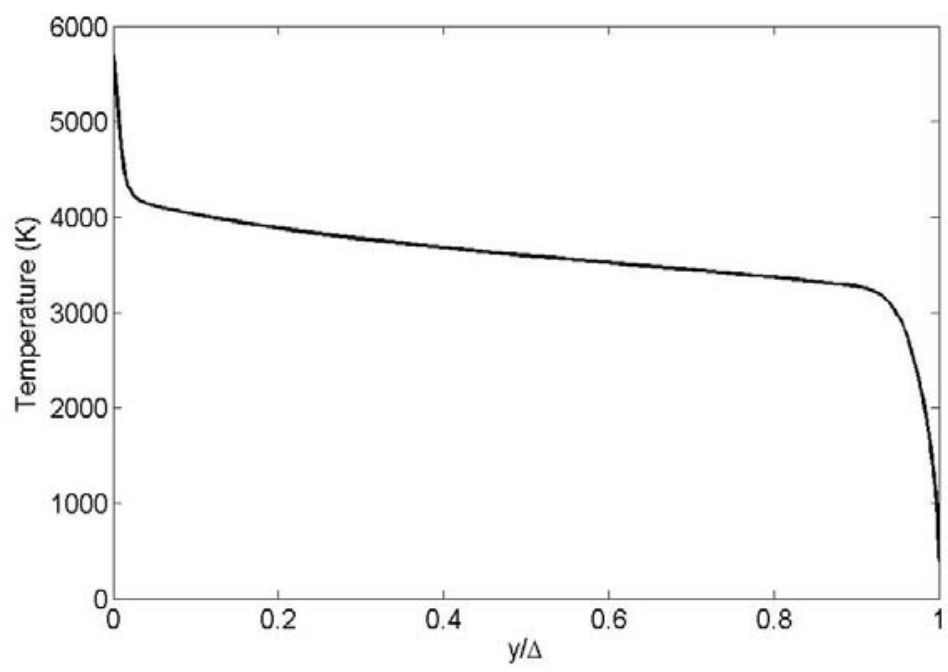

Figure 9: Stagnation line temperature profile from US3D numerical computations for the 1.5 inch sphere.

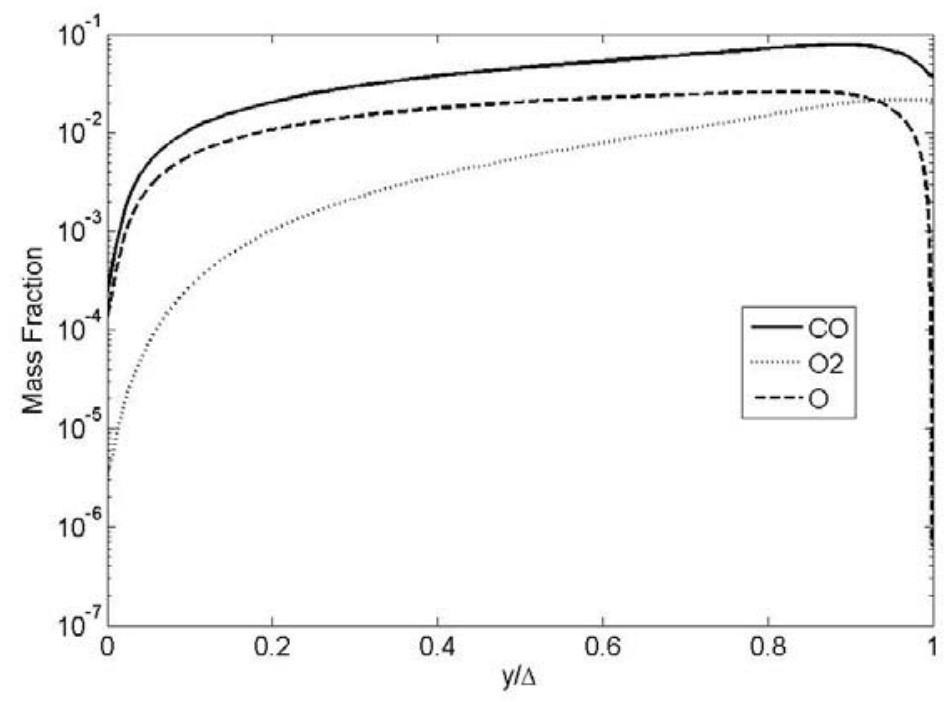

Figure 10: Mass fraction profiles for $\mathrm{CO}, \mathrm{O}$ and $\mathrm{O}_{2}$ from US3D numerical computation for the 1.5 inch sphere. 


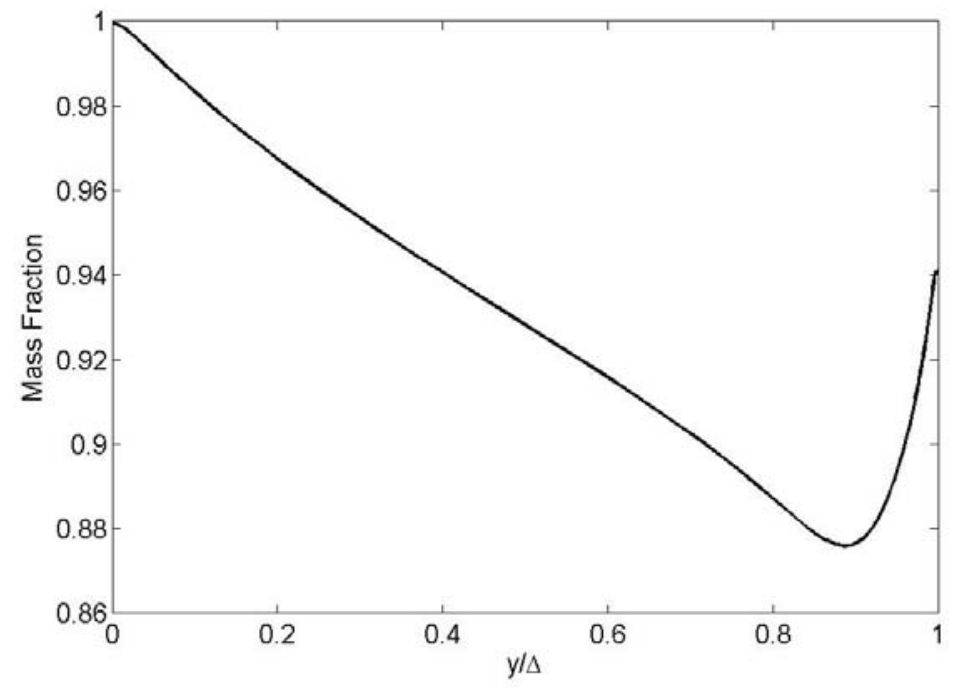

Figure 11: $\mathrm{CO}_{2}$ mass fraction profile from US3D numerical computation for the 1.5 inch sphere.

case, Figure $12 \mathrm{c}$ ), the maximum bow shock gradient with respect to the horizontal (freestream) has shifted towards the windward side. As measured from experiment, the vertical shift of this location is $8.5 \mathrm{~mm}$. To quantify the comparison between the predictions and experiments, an edge detection algorithm was used to extract the shock shape. For the 11 degree case, the average horizontal displacement at each given vertical location between numerical and experimental result is 1.64 pixels. With a minimum resolution of 1 pixel, restricting the accuracy to approximately $0.06 \mathrm{~mm}$, this agreement is excellent, as seen in Figure 13 which shows the comparison between simulation and experiment. The 16 degree case is also shown, Figure 14, for which the average horizontal displacement was calculated to be 2.49 pixels.

We compare the measured shock shape at zero angle of attack with the experimental and computational results from previous studies, Figure 15. The stand-off distance is a strong function of the density ratio across the shock. Despite the difference between the LENS X and HET frozen Mach numbers, the density ratios differ by about $15 \%$ and as such, to first-order it is appropriate to scale the images by the model diameter. Therefore, to first-order we see very good agreement between our result and that observed in the LENS X expansion tunnel. ${ }^{10}$ Calculated shapes at the conditions of the LENS X experiments are also in good agreement with the present measurements.

\section{Laminar Heat Flux and Catalytic Heating}

Extensive work has been completed using heat transfer measurements for $\mathrm{CO}_{2}$ aerothermodynamic studies. For a configuration with a similar corner-nose radius ratio as the MSL, Stewart and Chen reported a $13.76 \%$ difference between experiment and simulation. ${ }^{6}$ For the Pathfinder geometry (70-degree sphere cone), Hollis and Perkins measured heat transfer on Macor models using palladium thin-film gauges. ${ }^{9}$ Computed forebody heating rates agreed well with measurements except those readings near the stagnation point. ${ }^{40}$ They attributed this difference to the computational 


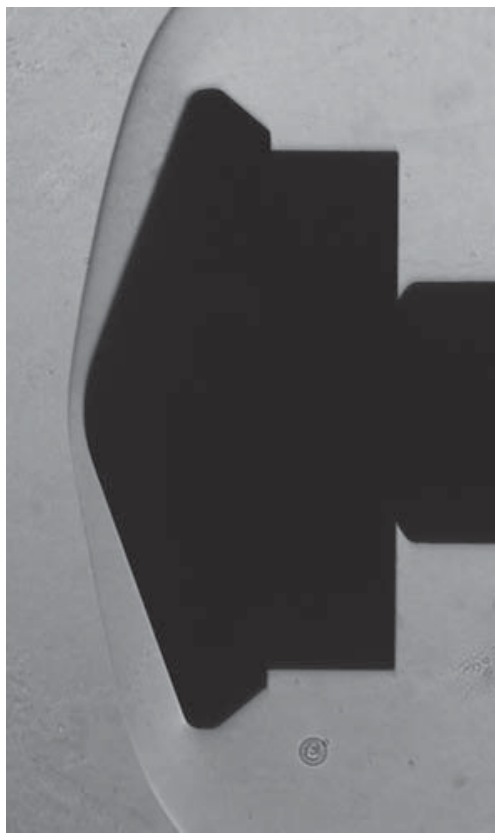

a)

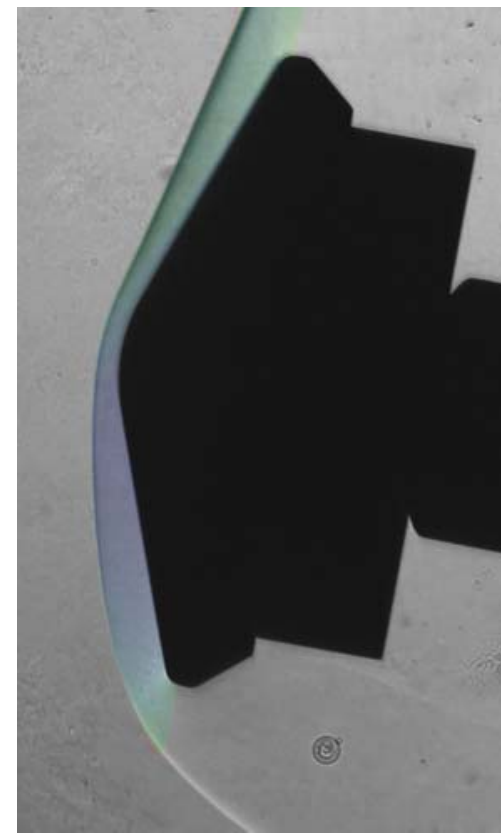

b)

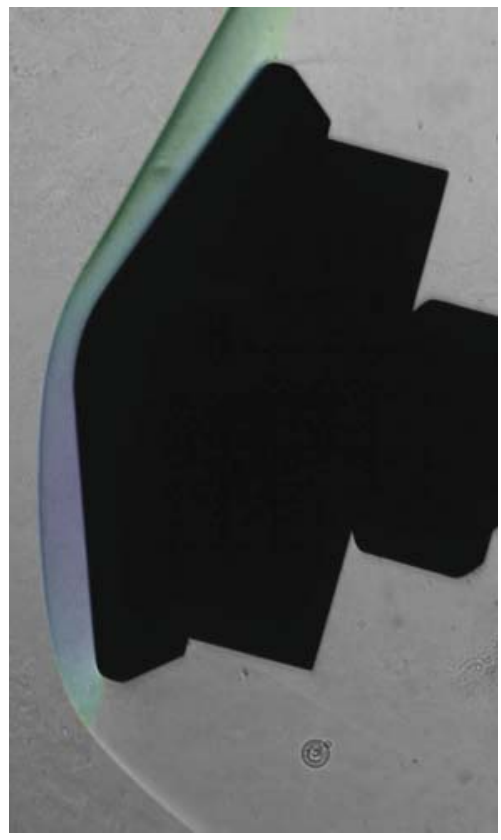

c)

Figure 12: Schlieren images of bow shock shapes over the MSL geometry at angles of attack of a) 0, b) 11 and c) 16 degrees. For the 11 and 16 degree cases, the simulation results have been overlayed onto the experimental image.

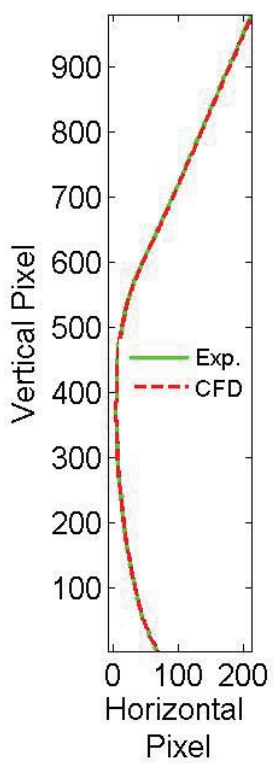

Figure 13: Comparison between experimental (solid line) and numerical (dashed line) bow shock front shapes over the MSL at angle of attack of 11 degrees. In the figure, 1 pixel is approximately equal to $0.06 \mathrm{~mm}$. 


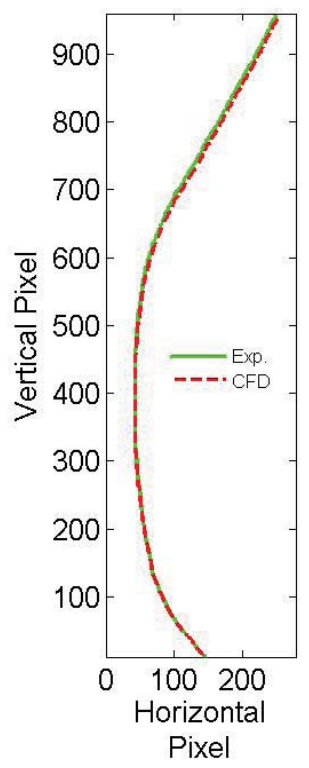

Figure 14: Comparison between experimental (solid line) and numerical (dashed line) bow shock front shapes over the MSL at angle of attack of 16 degrees. In the figure, 1 pixel is approximately equal to $0.06 \mathrm{~mm}$.

grid and uncertainties in the physical models. For a variety of run conditions, Hollis et al. found that windside heating augmentation was not correlated with Re despite such a correlation being identified in perfect-gas air flows for the same configurations. ${ }^{18}$ Thermocouple data was obtained for a variety of run conditions in the T5 facility. ${ }^{3}$ In a LENS I study, thermocouple data was collected on a MSL model at 11-degree angle of attack. ${ }^{41}$ Based upon these results, and at the same conditions, further studies were commissioned and heat transfer data collected using thermocouples, thin-film gages and calorimeters. ${ }^{12}$ A large volume of aeroheating data also exists that was obtained in different wind tunnel facilities including the NASA Langley 20-inch Mach 6 wind tunnel, ${ }^{18,42-44}$ the NASA Langley 31-inch Mach 10 wind tunnel ${ }^{8}$ and T9 at AEDC $^{45}$ (Arnold Engineering Development Center). Wind tunnel data was preferred for capsule selection studies due to the repeatability of operating conditions and well defined thermodynamic conditions (perfect gas). However, this entire dataset cannot speak to any thermochemical influences and is mentioned here for completeness.

Extensive investigations into the influence of wall catalysis boundary conditions upon surface heating in high-enthalpy carbon dioxide flow fields have been completed in the LENS facilities. ${ }^{12,18}$ MacLean and Holden compared heat transfer results with different catalytic boundary conditions. Discrepancies between the experimental surface heat transfer results and computation in the reflected shock tunnel facilities for three different high-enthalpy $\mathrm{CO}_{2}$ run conditions $\left(\mathrm{h}_{0}=5.63,5.99\right.$ and $8.65 \mathrm{MJ} / \mathrm{kg})^{12}$ were observed. At the low-enthalpy condition $\left(\mathrm{h}_{0}=1.89 \mathrm{MJ} / \mathrm{kg}\right)$, the overall agreement was very good. MacLean and Holden conclude that freestream uncertainty, and hence vibrational relaxation processes within the nozzle, is a contributing factor to, although not a full explaination of, these differences. Results from the CUBRC studies found that the experimental 


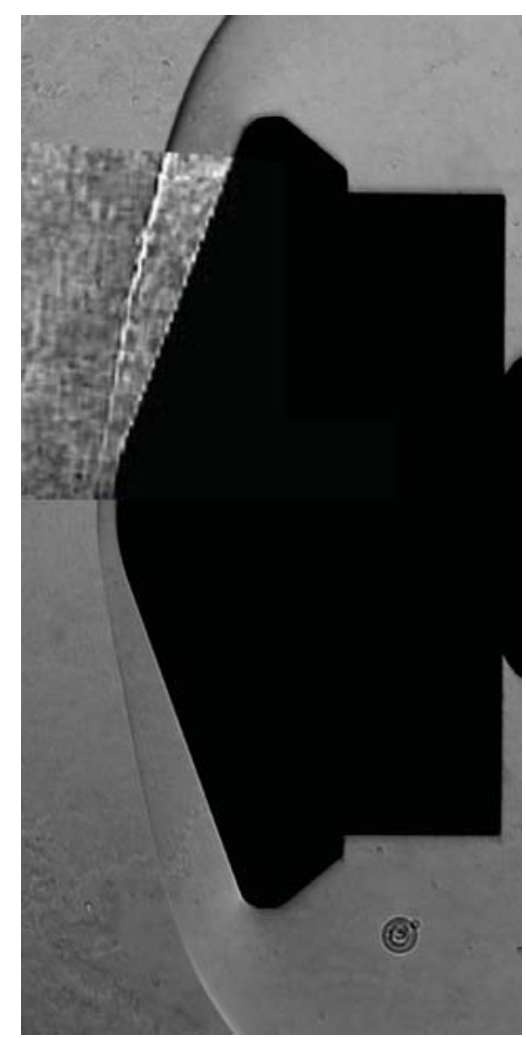

a)

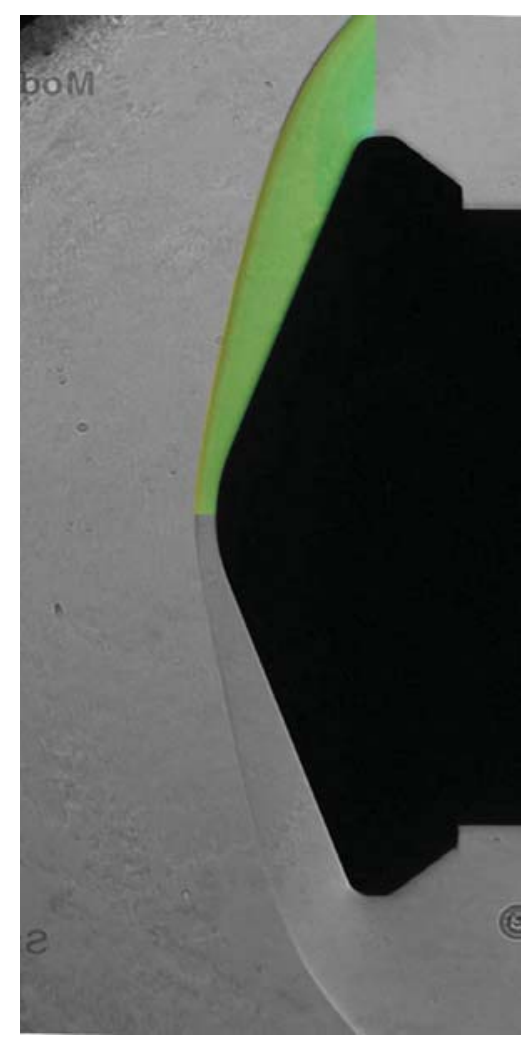

b)

Figure 15: Comparison of the present data with a) CUBRC LENS X data ${ }^{10}$ and b) DPLR simulations for the MSL model at zero angle of attack. ${ }^{10}$ Good agreement is observed with simulations, and for both expansion tunnel experiments. 
heating rates fell between non-catalytic and super-catalytic boundary conditions, which suggested that finite-rate catalysis existed at all points on the surface. ${ }^{12}$ In the T5 facility, super-catalytic predictions best matched the laminar windside data while the turbulent leeside data best matched a non-catalytic wall. ${ }^{3}$ In all of the above cases, heat transfer prediction issues occured despite very good pressure distribution agreement.

As previously discussed in Section III, heat flux in this study is measured using in-house constructed type E thermocouples based upon designs used at Caltech. Gage uncertainty is $\pm 8 \%$ based upon the calculations of Davis. ${ }^{20}$ We first measure the stagnation point heat flux measurements on a $25.4 \mathrm{~mm}$ diameter stainless steel sphere. From three repeat experiments, the average heat flux across the test time is found to be $6.73 \pm 0.55 \mathrm{MW} / \mathrm{m}^{2}$. The semi-empirical prediction of Sutton and Graves, ${ }^{46}$ which is an extension of the theory of Fay Riddell, ${ }^{39}$ and US3D numerical results were used for comparison. The theory of Fay and Riddell assumes an equilibrium boundary layer, which is reasonable given the extent of the equilibrium region in the shock layer predicted in Figure 5a). The prediction of Sutton and Graves is $6.85 \mathrm{MW} / \mathrm{m}^{2}$, which agrees well within the experimental uncertainty of the gages. The upper and lower bounds of the US3D prediction, corresponding to super-catalytic and non-catalytic simulations respectively, were $7.34 \mathrm{MW} / \mathrm{m}^{2}$ and $6.93 \mathrm{MW} / \mathrm{m}^{2}$, placing the experimental result closer to a non-catalytic wall.

Since the MSL model was constructed of tool steel, two cylindrical models, one of 316 stainless steel and one of A2 tool steel were next tested. Both cylinders were instrumented with a gauge mounted on the vertical axis of symmetry at a 45 degree angle. Figure 16 shows the comparison between two gauges in terms of the detected temperature rise. The temporal offset occurs only due to shot-to-shot variation in triggering. For heat transfer calculation, it is the gradient of the temperature history that is important and, as shown in Figure 16, the gradients appear to be very similar. At the 45 degree location, the average heat flux measured in repeat experiments was $2.55 \mathrm{MW} / \mathrm{m}^{2}$ and $2.53 \mathrm{MW} / \mathrm{m}^{2}$ on the tool and stainless steel models respectively. It is concluded that the heat flux measurements are not influenced by model material for these two steels.

A sample heat flux measurement obtained at the MSL nose for a 0 degree angle of attack is shown in Figure 17. At the beginning of the test time, it was observed that the instantaneous heat flux exhibited transient behavior, displaying primary and secondary peaks as seen in Figure 17. The primary large peak is always observed while the secondary smaller peak is not always present. It is postulated that the steep increase in heat flux is a perturbed response of the gage arising from the sharp temperature difference across the secondary interface, separating the relatively hot accelerator gas from the relatively cold test gas. From perfect gas predictions, this temperature difference is estimated to be approximately $5700 \mathrm{~K}$. Pitot pressure traces indicate that the width of the secondary interface is approximately $5 \mu \mathrm{s}$, which is on the same order as the width of the primary peak in Figure 17. To examine the effect of the transient behavior, the average heat flux is calculated for different sampling windows, Figure 17. In each calculation, the end of the test time is fixed (in this case at $13.06 \mathrm{~ms}$ ) and the sampling window changed by changing the start of the test time, $t_{\text {start }}$. For example, in the figure, as $t_{\text {start }}$ increases along the abscissa, the sampling window decreases. As the sampling window includes less and less of the peaks, the instantaneous and average traces converge. Furthermore, as expected based upon the large magnitude of the primary peak, the gradient of the average heat flux is much more pronounced when the primary peak is included in the calculation. Therefore, the incipient heat flux behavior is attributed to gage acclimatization to the large temperature difference across the secondary interface and as such is not included in the average heat flux calculation. The start of the test time is taken to be the 


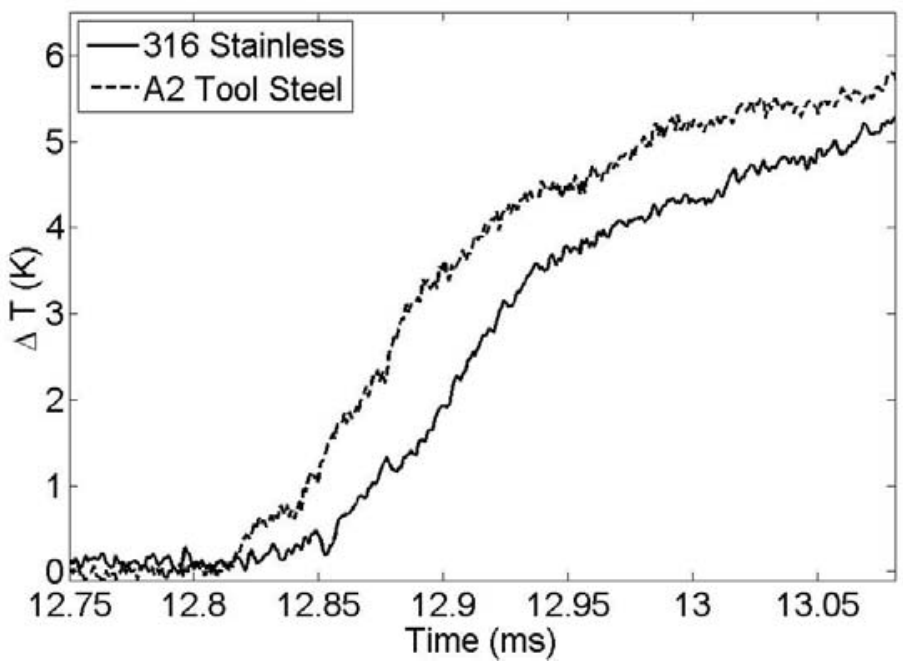

Figure 16: Change in temperature time history traces detected by two different thermocouples on A2 and 316 stainless steel cylinder models.

time at which the instantaneous heat flux falls within $15 \%$ of the average value. For example, in this case the start of the test time for the average heat flux calculation is taken to be $12.97 \mathrm{~ms}$, corresponding to a $90 \mu$ s test time.

The MSL model was instrumented with 11 thermocouples along the line of symmetry, with 5 on each side of the nose location. Repeat experiments were conducted for each of the three angle of attack conditions. The heat transfer distributions at the three angle of attacks are shown in Figures 18-20. Measurements were taken at selected locations, corresponding to the nose tip and \pm 4.3, 8.6 and $17 \mathrm{~mm}$ offset from the nose tip. The results from these distributions capture the general trends observed in previous MSL studies in a high-enthalpy shock tunnel. ${ }^{18}$ The nose heat transfer decreases with increasing angle of attack, which is indicative of the stagnation point shifting to the windward side as observed in Figures 12 a)-c). At 16 degrees, the average measured heat flux is $5.11 \mathrm{MW} / \mathrm{m}^{2}$, which is approximately a $14 \%$ reduction compared to the 0 degree configuration. On the windward side, the heat fluxes appear to be invariant with angle of attack for the angles considered. Additionally, the asymmetric nature of the curve has been captured at the 11 and 16 degree cases, whereby the leeward side measurements (at the same radial location magnitude) are lower than those on the windward side. For the current experiments, no transition is expected or observed given the Reynolds number and the scale of the model.

In each case, for Figures 18-20, the experimental measurement is compared to non-catalytic and super-catalytic surface boundary condition simulations. In general, accounting for the experimental uncertainty, the data falls within the bounds of the two solutions. Due to the lower degree of freestream dissociation in the HET compared to LENS I for the same stagnation enthalpy, the relative difference between the non-catalytic and super-catalytic solutions is not as large. Unfourtunately, this smaller difference and the experimental uncertainty of the gages means that it is not possible to conclude which boundary condition provides the best agreement.

At all three angles of attack, experimentally measured heat fluxes at the outermost extent of 


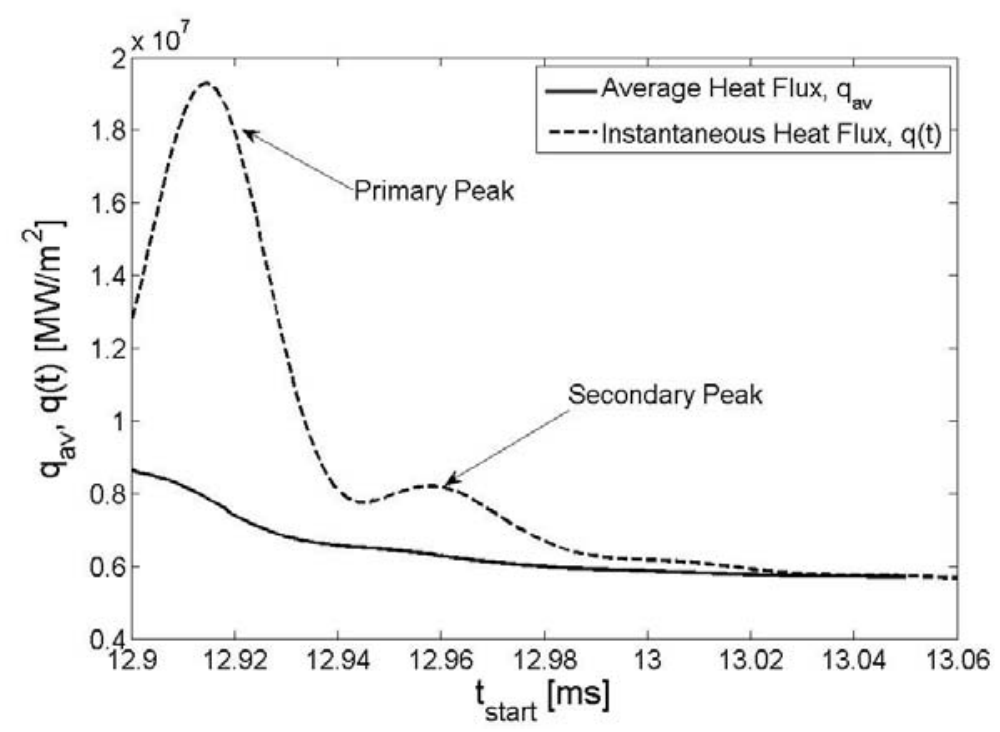

Figure 17: Comparison of instantaneous heat flux and the calculated heat flux during the test time.

the model are above the super-catalytic solution. Such a result appears to be anomalous as the super-catalytic solution enforces full surface recombination, irregardless of the local species mole fractions, and therefore represents an aphysical upper bound on the heat flux. Hollis et al. observed windside heating augmentation, which was not found to correlate with Reynolds Number, in the LENS I facility. ${ }^{18}$ In this study, however, both windside and leeside elevated heating levels are observed. At this stage, the reason for this observation is unknown.

\section{Conclusions}

Experiments are conducted in an expansion tube facility to visualize bow shock shapes and measure heat flux over blunt bodies in a hypervelocity carbon dioxide flow. The blunt bodies of interest are spheres of varying diameters and a scaled version of the Mars Science Laboratory aeroshell. This study was motivated by previous experiments at the CUBRC hypervelocity facilities which found that substantially different shock stand-off distances were measured in different impulse facilities. One contributing factor is that the free stream carbon dioxide thermochemistry depends on the means by which the flow is accelerated to high velocities. To address this question and provide complementary results to those from CUBRC, we carry out the present experiments in the Hypervelocity Expansion Tube. Experimental shock layer shapes for different geometries, including spheres and the MSL forebody, are compared with simulations using the University of Minnesota solver, US3D, which incorporates detailed $\mathrm{CO}_{2}$ thermochemical modeling.

A test condition, labeled RC5, was selected by matching the stagnation enthalpy $(5.63 \mathrm{MJ} / \mathrm{kg}$ ) with a CUBRC test condition. Spheres with varying diameters were chosen as benchmark models for which shock stand-off distances could be compared with existing data and theory. Excellent agreement was obtained between simulation and experiment for different diameters. Sphere stagnation point heat transfer measurements were in good agreement with semi-empirical fits and 


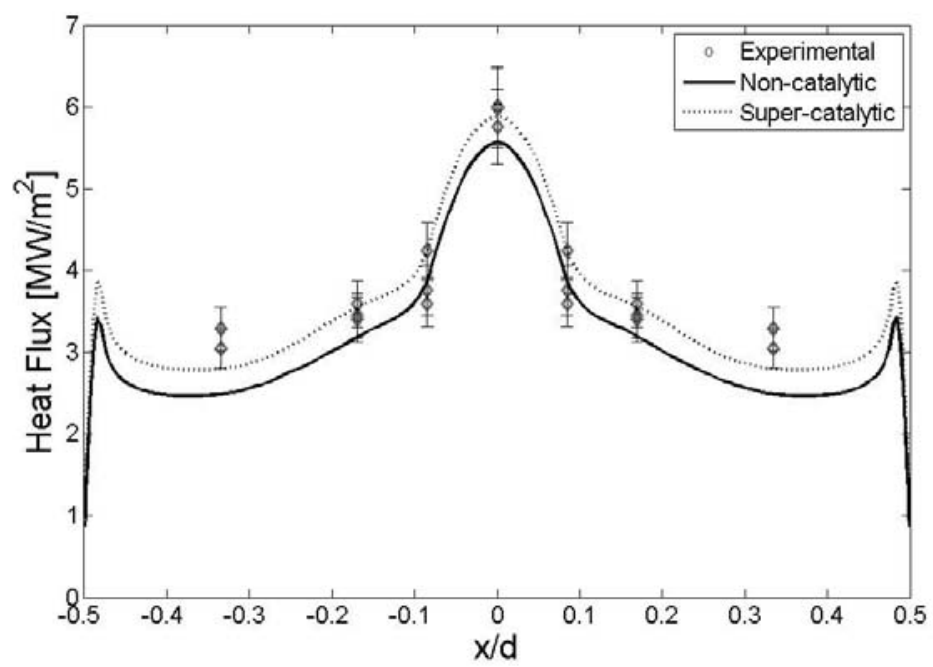

Figure 18: Heat flux measurements at selected locations along the centerline of the MSL geometry for 0 degree angle of attack. Numerical simulations for both non-catalytic and super-catalytic conditions are shown.

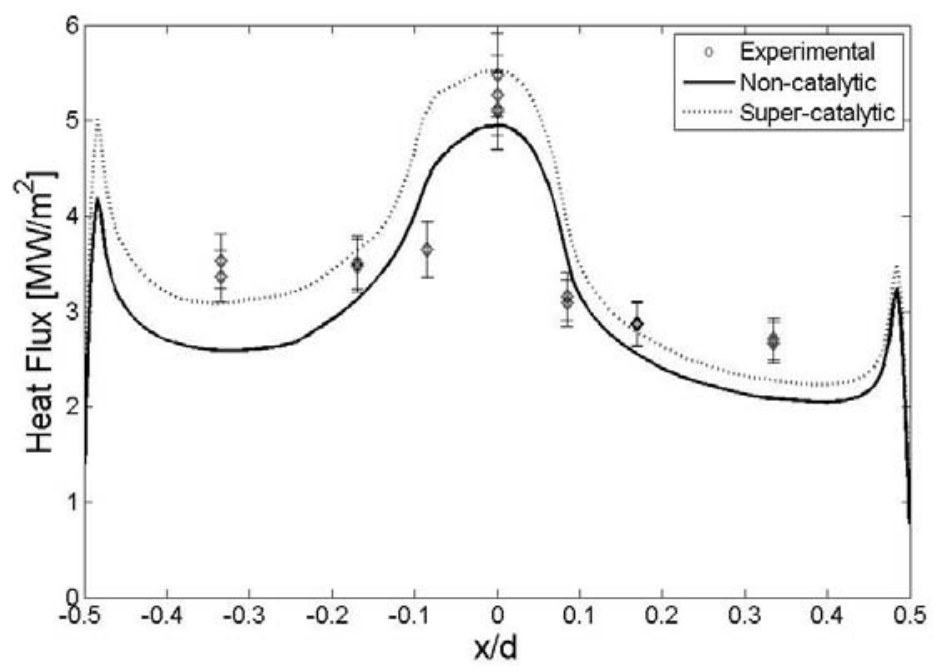

Figure 19: Heat flux measurements at selected locations along the centerline of the MSL geometry for 11 degree angle of attack. Numerical simulations for both non-catalytic and super-catalytic conditions are shown. 


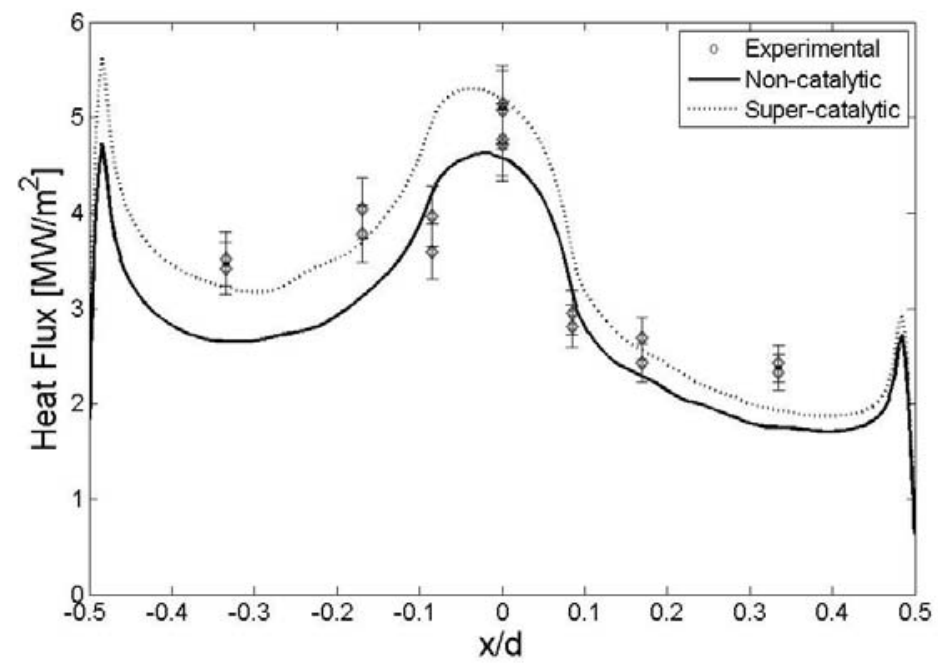

Figure 20: Heat flux measurements at selected locations along the centerline of the MSL geometry for 16 degree angle of attack. Numerical simulations for both non-catalytic and super-catalytic conditions are shown.

non-catalytic numerical results.

The scaled MSL model was next tested in this flow field. Shock shapes were visualized and heat transfer measurements were made at three different angles of attack: 0, 11, and 16 degrees. Excellent agreement in the shock shapes between simulations and experiments was obtained at angles of attack of 11 and 16 degrees. The present experiments are also in very good agreement with CUBRC expansion tunnel data at zero angle of attack, implying the stagnation enthalpy and velocity are reasonable first-order matching parameters for these measurements in different expansion tube facilities. The results confirm facility-independence for the same type of flow acceleration. The heat transfer data follow the general trends observed in previous experiments. Peak-heating shifted to the windward side with non-zero angle of attack. Windward side heat transfer values appear quite insensitive to angle of attack, while the leeward side values decrease appreciably with increasing angle of attack. In general, accounting for the experimental uncertainty, the data falls within the bounds of the two non-catalytic and super-catalytic numerical solutions.

\section{Acknowledgements}

For thermocouple implementation and design advice, the authors would like to thank Professor Hans Hornung, Drs Simon Sanderson, Jean-Paul Davis, Bahram Valiferdowski, Ivett Leyva, Eric Marineau and Adam Rasheed. For co-ordination with CUBRC and expansion tube gas dynamic discussion, the authors thank Aaron Dufrene for his valuable input. 


\section{References}

${ }^{1}$ Wen, C. Y. and Hornung, H. G., "Non-equilibrium dissociating flow over spheres," Journal of Fluid Mechanics, Vol. 299, 1995, pp. 389-405.

${ }^{2}$ Hornung, H. G. and Smith, G. H., "The Influence of Relaxation on Shock Detachment," Journal of Fluid Mechanics, Vol. 93, No. Pt.2, 1979.

${ }^{3}$ Wright, M. J., Olejniczak, J., Brown, J. L., Hornung, H. G., and Edquist, K. T., "Computational Modeling of T5 Laminar and Turbulent Heating Data on Blunt Cones, Part 2: Mars Applications," 43rd AIAA Aerospace Sciences Meeting and Exhibit, 2005, AIAA Paper 2005-177.

${ }^{4}$ Wright, M. J., Tang, C. Y., Edquist, K. T., Hollis, B. R., Krassa, P., and Campbell, C. A., "A Review of Aerothermal Modeling for Mars Entry Missions," 48th AIAA Aerospace Sciences Meeting and Exhibit, 2010, AIAA Paper 2010-443.

${ }^{5}$ Edquist, K., Dyakonov, A., Wright, M., and Tang, C., "Aerothermodynamic Environments Definition for the Mars Science Laboratory Entry Capsule," 45th AIAA Aerospace Sciences Meeting, 2007, AIAA Paper 2007-1206.

${ }^{6}$ Stewart, D. A. and Chen, Y. K., "Hypersonic Convective Heat Transfer over 140-deg Blunt Cones in Different Gases," Journal of Spacecraft and Rockets, Vol. 31, No. 5, 1994, pp. 735-743.

${ }^{7}$ Netterfield, M. P., Mazoue, F., Marraffa, L., Kastell, D., and Eitelberg, G., "Experiments and Computations on a Blunt Body in High Enthalpy $\mathrm{CO}_{2}, " 31$ st AIAA Thermophysics and Heat Transfer Conference, 1996.

${ }^{8}$ Hollis, B. R. and Perkins, J. N., "High-Enthalpy and Perfect-Gas Heating Measurements on a Blunt Cone," Journal of Spacecraft and Rockets, Vol. 33, No. 5, 1996, pp. 628-634.

${ }^{9}$ Hollis, B. R. and Perkins, J. N., "High-Enthalpy Aerothermodynamics of a Mars Entry Vehicle Part 1: Experimental Results," Journal of Spacecraft and Rockets, Vol. 34, No. 4, 1997, pp. 449-456.

${ }^{10}$ Holden, M. S., Wadhams, T. P., MacLean, M., and Mundy, E., "Experimental Studies in LENS I and X to Evaluate Real Gas Effects on Hypervelocity Vehicle Performance," 45th AIAA Aerospace Sciences Meeting and Exhibit, 2007, AIAA Paper 2007-204.

${ }^{11}$ MacLean, M. and Holden, M. S., "Numerical Assesment of Data in Catalytic and Transitional Flows for Martian Entry," 9th AIAA/ASME Joint Thermophysics and Heat Transfer Conference, 2006, AIAA Paper 2006-2940.

${ }^{12}$ Holden, M. S. and MacLean, M., "Catalytic Effects on Heat Transfer Measurements for Aerothermal Studies with $\mathrm{CO}_{2}, " 44$ th AIAA Aerospace Sciences Meeting and Exhibit, 2006, AIAA Paper 2006-182.

${ }^{13}$ Marschall, J., Copeland, R. A., Hwang, H. H., and Wright, M. J., "Surface Catalysis Experiments on Metal Surfaces in Oxygen and Carbon Monoxide Mixtures," 44th AIAA Aerospace Sciences Meeting and Exhibit, 2006, AIAA Paper 2006-181.

${ }^{14}$ Nompelis, I., Drayna, T. W., and Candler, G. V., "Development of a Hybrid Unstructured Implicit Soliver for the Simulation of Reacting Flows Over Complex Geometries," 34th AIAA Fluid Dynamics Conference, 2004, AIAA Paper 2004-2227.

${ }^{15}$ Dufrene, A., Sharma, M., and Austin, J. M., "Design and characterization of a hypervelocity expansion tube facility," Journal of Propulsion and Power, Vol. 23, No. 6, 2007, pp. 1185-1193.

${ }^{16}$ Sharma, M., "Further Development and Experimentation with the Hypervelocity Expansion Tube," M.S. Thesis, University of Illinois at Urbana-Champaign, 2007.

${ }^{17}$ McGilvray, M., Austin, J. M., Sharma, M., Jacobs, P. A., and Morgan, R. G., "Diagnostic modelling of an expansion tube operating condition," Shock Waves, Vol. 19, No. 1, 2009, pp. 59-66.

${ }^{18}$ Hollis, B. R., Leichy, D. S., Wright, M. J., Holden, M. S., Wadhams, T. P., MacLean, M., and Dyakonov, A., "Transition Onset and Turbulent Heating Measurements for the Mars Science Laboratory Entry Vehicle," 43rd AIAA Aerospace Sciences Meeting and Exhibit, 2005, AIAA Paper 2005-1437.

${ }^{19}$ Sanderson, S. R., "Shock wave interaction in hypervelocity flow," PhD Thesis, California Institute of Technology, 1995.

${ }^{20}$ Davis, J.-P., "High-Enthalpy Shock/Boundary-Layer Interaction on a Double Wedge," PhD Thesis, California Institute of Technology, 1999.

${ }^{21}$ Rasheed, A., "Passive Hypervelocity Boundary Layer Control Using an Ultrasonically Absorptive Surface," PhD Thesis, California Institute of Technology, 2001.

${ }^{22}$ Croarkin, M. C., Guthrie, W. F., Burns, G. E., Kaeser, M., and Strouse, G. F., "Temperature-Electromotive 
Force Referance Function and Tables for the Letter-Designated Thermocouple Types Based on the ITS-90," Monograph 175, National Institute of Standard Technologies, 1993.

${ }^{23}$ Flaherty, W. and Austin, J. M., "Comparative Surface Heat Transfer Measurements in Hypervelocity Flow," 48th AIAA Aerospace Sciences Meeting and Exhibit, 2010, AIAA Paper 2010-671.

${ }^{24}$ Doraiswamy, S., Kelley, J. D., and Candler, G. V., "Vibrational Modeling of $\mathrm{CO}_{2}$ in High Enthalpy Nozzle Flows," Journal of Thermophysics and Heat Transfer, Vol. 24, No. 3, 2010, pp. 183-190.

${ }^{25}$ Macrossan, M. N., "Hypervelocity flow of dissociating nitrogen downstream of a blunt nose," Journal of Fluid Mechanics, Vol. 217, 1990, pp. 167-202.

${ }^{26}$ Sharma, M., Austin, J. M., Glumac, N. G., and Massa, L., "NO and OH Spectroscopic Vibrational Temperature Measurements in a Post-Shock Relaxation Region," AIAA Journal, Vol. 48, No. 7, 2010, pp. $1434-1443$.

${ }^{27}$ Paull, A. and Stalker, R. J., "Test flow disturbances in an expansion tube," Journal of Fluid Mechanics, Vol. 245, 1992, pp. 493-521.

${ }^{28}$ Mizuno, H., Sawada, K., and Sasoh, A., "Numerical Analysis of Carbon Dioxide Flowfield in Expansion-Tube," 8th AIAA/ASM Joint Thermophysics and Heat Transfer Conference, 2002, AIAA Paper 2002-3221.

${ }^{29}$ Lick, W., "Inviscid flow of a reacting mixture of gases around a blunt body," Journal of Fluid Mechanics, Vol. 9, No. 1, 1960, pp. 128-144.

${ }^{30}$ Hall, J. G., Eschendoeder, A. Q., and Marrone, P. V., "Blunt-nose inviscid ariflows with coupled nonequilibrium processes," Journal of Aeronautical Space Sciences, Vol. 29, No. 9, 1962, pp. 1038-1051.

${ }^{31}$ Hornung, H. G., "Non-equilibrium dissociating nitrogen flows over spheres and circular cylinders," Journal of Fluid Mechanics, Vol. 53, 1972, pp. 149-176.

${ }^{32}$ Inger, G. R., Higgins, C., and Morgan, R., "Shock Standoff on Hypersonic Blunt Bodies in Nonequilibrium Gas Flows," Journal of Thermophysics and Heat Transfer, Vol. 16, No. 2, 2002.

${ }^{33}$ Belouaggadia, N., Olivier, H., and Brun, R., "Numerical and theoretical study of the shock stand-off distance in non-equilibrium flows," Journal of Fluid Mechanics, Vol. 607, 2008, pp. 167-197.

${ }^{34}$ Olivier, H., "A theoretical model for the shock stand-off distance in frozen and equilibrium flow," Journal of Fluid Mechanics, Vol. 413, 2000, pp. 345-353.

${ }^{35}$ McGilvray, M., Austin, J. M., Sharma, M., Jacobs, P. A., and Morgan, R. G., "Diagnostic modelling of an expansion tube operating condition for a hypersonic shear layer experiment," Proceedings of the 16th Australasian Fluid Mechanics Conference, Gold Coast, Australia, 2007.

${ }^{36}$ Wegener, P. P. and Buzyna, G., "Experiments on shock stand-off distance in non-equilibrium flow," Journal of Fluid Mechanics, Vol. 37, pt. 2, No. 2, 1969, pp. 325-335.

${ }^{37}$ Wen, C., "Hypervelocity Flow over Spheres," PhD Thesis, California Institute of Technology, 1994.

${ }^{38}$ McBride, B. J. and Gordon, S., "Computer Program for Calculation of Complex Chemical Equilibrium Compositions and Applications, II. Users Manual and Program Description," NASA CR-1311, 1996.

${ }^{39}$ Fay, J. A. and Riddell, F. R., "Theory of stagnation point heat transfer in dissociated air," Journal of the Aeronautical Sciences, Vol. 25, No. 2, 1999, pp. 73-85.

${ }^{40}$ Hollis, B. R. and Perkins, J. N., "High-Enthalpy Aerothermodynamics of a Mars Entry Vehicle Part 1: Computational Results," Journal of Spacecraft and Rockets, Vol. 34, No. 4, 1997, pp. 457-463.

${ }^{41}$ Holden, M. S., Wadhams, T. P., Smolinski, G. J., MacLean, M., Harvey, J. K., and Walker, B. J., "Experimental and Numerical Studies on Hypersonic Vehicle Performance in the LENS Shock and Expansion Tunnels," 44th AIAA Aerospace Sciences Meeting and Exhibit, 2006, AIAA Paper.

${ }^{42}$ Edquist, K. T., Liechty, D. S., Hollis, B. R., Alter, S. J., and Loomis, M. P., "Aeroheating Environments for a Mars Science Lander," Journal of Spacecraft and Rockets, Vol. 43, No. 2, 2006, pp. 330-339.

${ }^{43}$ Liechty, D. S., Hollis, B. R., and Edquist, K. T., "Mars Science Laboratory Experimental Aerothermodynamics with Effects of Cavities and Control Surfaces," Journal of Spacecraft and Rockets, Vol. 43, No. 2, 2006, pp. 340-353.

${ }^{44}$ Liechty, D. S. and Hollis, B. R., "Transition Due to Heat Shield Cavities on a Mars Entry Vehicle," Journal of Spacecraft and Rockets, Vol. 43, No. 2, 2006, pp. 354-366.

${ }^{45}$ Hollis, B. R. and Collier, A., "Turbulent Aeroheating Testing of Mars Science Laboratory Entry Vehicle in Nitrogen," 45th AIAA Aerospace Sciences Meeting, 2007, AIAA Paper 2007-1208.

${ }^{46}$ Sutton, K. and Graves, A. R., "A general stagnation-point convective-heating equation for arbitary gas mixtures," Tech. rep., NASA, 1971. 